Review

\title{
Flavonoids: Hemisynthesis, Reactivity, Characterization and Free Radical Scavenging Activity
}

\author{
Nour-Eddine Es-Safi ${ }^{1,2, *}$, Souhila Ghidouche ${ }^{1}$ and Paul Henri Ducrot ${ }^{1, *}$ \\ ${ }^{1}$ Unité de Phytopharmacie et Médiateurs Chimiques, INRA, Route de Saint-Cyr, 78026 Versailles \\ Cedex, France; E-mails: soughid@yahoo.com (Guidouche); ducrot@versailles.inra.fr (Ducrot) \\ 2 Laboratoire de Chimie Organique et d'Etudes Physico-Chimiques, Pôle de Compétences \\ Pharmacochimie. Ecole Normale Supérieure, B.P 5118 Takaddoum Rabat, Morocco
}

* Authors to whom correspondence should be addressed; E-mails: nouressafi@yahoo.fr (Es-Safi); ducrot@versailles.inra.fr (Ducrot)

Received: 29 May 2007; in revised form: 17 September 2007 / Accepted: 18 September 2007 / Published: 26 September 2007

\begin{abstract}
Phenolic compounds form one of the main classes of secondary metabolites. They display a large range of structures and they are responsible for the major organoleptic characteristics of plant-derived-foods and beverages, particularly color and taste properties and they also contribute to the nutritional qualities of fruits and vegetables. Phenolic compounds are also highly unstable compounds which undergo numerous enzymatic and chemical reactions during postharvest food storage and processing thus adding to the complexity of plant polyphenol composition. Among these compounds flavonoids constitute one of the most ubiquitous groups of all plant phenolics. Owing to their importance in food organoleptic properties and in human health, a better understanding of their structures, their reactivity and chemical properties in addition to the mechanisms generating them appears essential to predict and control food quality. The purpose of this work is an overview of our findings concerning the hemisynthesis, the reactivity and the enzymatic oxidation of some flavonoids and shed light on the mechanisms involved in some of these processes and the structures of the resulting products. The free radical scavenging activity of some of the synthesized compounds is also presented and a structure-activity relationship is discussed. The first part of this review concerns the synthesis and structural characterization of modified monomeric flavanols. The use of these compounds as precursor for the preparation of natural and modified dimeric
\end{abstract}


procyanidin derivatives was then explored through different coupling reactions. The full characterization of the synthesized compounds was achieved by concerted use of NMR and ESI-MS techniques. The free radical scavenging activity of some of the synthesized compounds was investigated. The second part of this review concerns the enzymatic oxidation of several flavonols by Trametes versicolor laccase. Most of the major oxidation products have been isolated as pure compounds and their structures unambiguously established through spectroscopic methods. Correlation between the structure of the oxidation product and the substitution pattern of the starting materials allows mechanistic features of this transformation to be elucidated.

Keywords: Polyphenols, flavonoids, flavanols, flavonols, flavones, procyanidins, dimerization, substituent effects, modified flavan-3-ols, synthesis, enzymatic oxidation, Trametes versicolor, antioxidant activity, DPPH.

\section{Introduction}

Phenolic compounds form one of the main classes of secondary metabolites. They possess a large range of structures, and contribute to the organoleptic and nutritional qualities of fruits and vegetables [1]. They are responsible for major organoleptic characteristics of plant-derived-foods and beverages, particularly color and taste properties. Among these compounds flavonoids constitute one of the major classes of all plant secondary metabolites derived from the phenyl propanoid pathway. They are recognized as one of the largest and most widespread class of plant constituents occurring throughout the plant kingdom, and are also found in substantial levels in commonly consumed fruits, vegetables and beverages. In seeds, they act in protection against predators and pathogens [2], increase seed coat (testa)-imposed dormancy [3,4] and protect against UV radiations [5]. These phytochemicals are often referred as antioxidants on account of their ability of protecting against damages caused by reactive oxygen species (ROS). By their ability to react and damage many structures in the body, ROS are involved in various related diseases such as cancer and atherosclerosis. Both natural and synthetic antioxidants have been shown to act against ROS and the use of antioxidants in food technology has shown them to enhance product stability, quality, and shelf life. Recent works have also mentioned the disadvantage of synthetic antioxidants, and their possible injurious properties for human health compared to natural antioxidants.

Flavonoids have aroused considerable interest because of their potential beneficial biochemical and antioxidant effects on human health. Most of the experimental results demonstrate that flavonoid compounds have several biological activities including radical scavenging, anti-inflammatory, antimutagenic, anti-cancer, anti-HIV, anti-allergic, anti-platelet and anti-oxidant activities [6]. Flavonoids are also highly unstable compounds which undergo numerous enzymatic and chemical reactions during postharvest food storage and processing thus adding to the complexity of plant polyphenol composition. Flavonoid structures are characterized by a 15-carbon (C6-C3-C6) backbone consisting of one oxygenated and two aromatic rings. They are grouped together into subclasses based on their 
basic chemical structures; the most common ones being flavanols, flavones, flavonols, isoflavones, flavanones, anthocyanins and chalcones.

Among these compounds flavanols, including proanthocyanidins (condensed tannins), constitute one of the most ubiquitous groups of all plant phenolics [7-10]. They are known to have powerful freeradical-scavenging activity [11], antioxidant activity [12] and anti-tumor-promoting effects [13]. Owing to the importance of proanthocyanidins in food organoleptic properties and in human health, a better understanding of their structures and chemical properties and of the mechanisms generating them appears essential to predict and control food quality.

Proanthocyanidins are generally mixtures of oligomers and polymers of flavan-3-ol units, linked either through carbon-carbon and/or carbon-oxygen bonds. The most encountered flavan-3-ols involved in proantocyanidin formation are derived from catechin 1a, epicatechin $\mathbf{1 b}$, gallocatechin 1c, or epigallocatechin 1d (Figure 1).

Figure 1. Structures of flavan-3-ol monomers (1a-1d) and oligo/polymers (2).

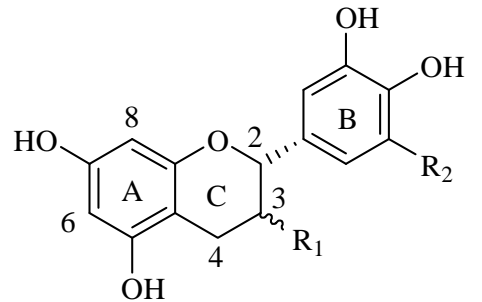

1a: $\mathrm{R}_{1}=\mathrm{OH}, \mathrm{R}_{2}=\mathrm{H} \quad$ catechin 1b: $\mathrm{R}_{1}=$ " $\mathrm{OH}, \mathrm{R}_{2}=\mathrm{H}$ epicatechin 1c: $\mathrm{R}_{1}=\backslash \mathrm{OH}, \mathrm{R}_{2}=\mathrm{OH}$ gallocatechin 1d: $\mathrm{R}_{1}=$ ". $\mathrm{OH}, \mathrm{R}_{2}=\mathrm{OH}$ epigallocatechin

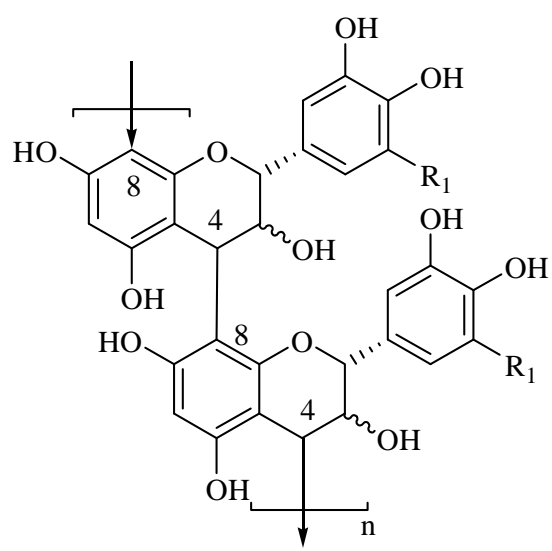

C4-C8 linkage

2a: $\mathrm{R}_{1}=\mathrm{H}$ Procyanidins

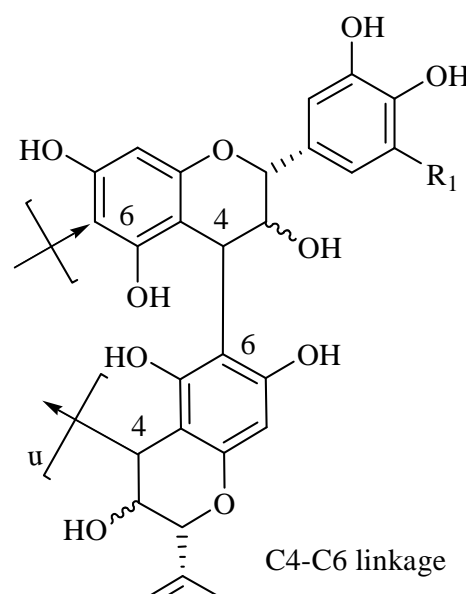

2b: $\mathrm{R}_{1}=\mathrm{OH}$ Prodelphinidins

The synthesis of proanthocyanidins 2 is generally accomplished by coupling the C-4 of an electrophilic flavanyl unit to a C-6/C-8 of a nucleophilic flavanyl unit. The nucleophilicity of the aromatic A-ring may play a crucial role in these coupling reactions, during which a new bond is established. The stability of proanthocyanidins is primarily dependent on that of this newly established linkage, which is sensible to acidic and alkalinic conditions and might a priori also be influenced by the type of flavanol unit. As well the reactivity of the electrophilic/nucleophilic species involved in the coupling reaction could also be influenced by the flavanol types.

In addition to the transformations involving chemical reactions of flavonoids, the enzymatic oxidation of polyphenols is very involved in numerous biological mechanisms. As the radicals formed through this oxidation process are relatively stable, they can undergo several coupling reactions. These coupling reactions are of major interest in lignin, tannin and melanin biosynthesis. However, these reactions are also responsible for the evolution of the polyphenol profile during the elaboration of plant and fruits derived foods and beverages. 
Indeed, when asked to discuss polyphenol oxidation induced browning in foods, those involved from production to processing, usually reflect on its detrimental influence. Some enzymatic browning reactions are nevertheless very beneficial to the overall acceptability of foods. Black, oolong and green tea are reliant on enzymatic browning for colour and flavour development. Some discussion occurs as to the contribution of enzymatic browning to colour development during coffee processing. Similarly, colour development in cacao is facilitated by polyphenol oxidase activity during fermentation. Polyphenol oxidases are also responsible for development of the characteristic golden brown colour in dried fruits such as grape fruits, prunes, dates and figs and blanching is generally required for inactivation of the enzyme after colour development, in order to minimize discolouration.

In a program dedicated to the study of the total synthesis [14-16], and the chemical [17-19] or enzymatic oxidation of polyphenols, we focused our interest on the mechanistic features arising from the structure of the oxidation products of flavonols by Trametes versicolor laccase. Indeed, the main transformations undergone by polyphenols in fruits and plants during food processing are caused by oxidative reactions catalysed by polyphenol oxidases, such as laccases, catechol oxidases and tyrosinases and by peroxidases. Oxidation proceeds in the presence of molecular oxygen for most polyphenol oxidases and with hydrogen peroxide for peroxidases [20,21]. Autoxidation and chemical oxidation processes may also occur [22].

Laccases are part of a large group of enzymes called blue copper oxidases and are present in plants as well in a large variety of fungi [23,24]. Assuming the course of the enzymatic oxidation of polyphenol to be more influenced by the chemical structure of the starting polyphenol than by the nature of the enzyme used, we turned to the use of Trametes versicolor laccase, a reliable, commercially available fungus enzyme with a low substrate specificity $[25,26]$ in order to study flavonol oxidations. We indeed preliminarily demonstrated with model compounds that this enzyme gave rise to the same oxidation products profile than other, more difficult to obtain from sustainable sources and less easy to handle, laccases or peroxidases from vegetal sources.

Taking into account the importance of flavonoids in both organoleptic properties and for human health, and in connection with the reactivity of polyphenols and the role played by these transformations in food organoleptic properties, during food processing, storage and ageing, we present in this work an overview of our findings concerning the hemisynthesis, the reactivity and the enzymatic oxidation of some flavonoids and shed light on the mechanisms involved in some of these processes and the structures of the resulting products. The free radical scavenging activity of some of the synthesized compounds is also presented and a structure-activity relationship is discussed.

In the hemisynthesis of modified flavanols our starting material was (+)-catechin, while two compounds with no hydroxy groups at C3, namely chrysin and luteolin, and three flavonols with an hydroxy group at C3 exhibiting various hydroxylation pattern on their B ring, namely kaempferol, quercetin and myricetin were used for the enzymatic oxidation. 


\section{Results and Discussion}

Synthesis of modified (+)-catechin derivatives

We started investigations on the synthesis of new modified monomeric units derived from catechin with the objective of exploring the impact of the A ring substitution on their biological properties. For this study, the six 8-substituted derivatives of flavan-3-ols, 3-8, in addition to taxifolin (9) were synthesized and their antioxidative activity investigated. The modified flavan-3-ols monomer derivatives described in this work are shown in Figure 2 and their synthesis pathways are depicted in Scheme 1. As can be noticed, the studied compounds were synthesized in their benzylated forms 11, 12, 14-16 and 23. Their free forms were obtained through deprotection in a MeOH/THF medium, under $\mathrm{H}_{2}$ and in presence of Pd as catalyst.

Figure 2. Structures of the studied modified flavan-3-ol monomers 3-9.<smiles>O=Cc1c(O)cc(O)c2c1O[C@H](c1ccc(O)c(O)c1)[C@H](O)C2</smiles>

3<smiles>Cc1c(O)cc(O)c2c1O[C@H](c1ccc(O)c(O)c1)C(O)C2</smiles>

4<smiles>Oc1ccc([C@@H]2Oc3c(O)cc(O)c(C(F)F)c3CC2O)cc1O</smiles>

7<smiles>Cc1c(O)cc(O)c2c1O[C@H](c1ccc(O)c(O)c1)C(O)C2</smiles>

5<smiles>Oc1ccc([C@H]2Oc3c(O)cc(O)c(C(F)(F)F)c3CC2O)cc1O</smiles>

8<smiles>Oc1cc(O)c2c(c1)C[C@@H](O)[C@H](c1ccc(O)c(O)c1)O2</smiles>

6

9

Compound $\mathbf{1 1}$ was prepared by action of trifluoacetic anhydride on tetrabenzylated catechin $\mathbf{1 0}$ following a Friedel-Craft's reaction on the nucleophilic C-8 position, as previously described [14,15]. Further reduction by $\mathrm{NaBH}_{4}$ afforded compound 12. Compound 14 was prepared starting from the pentabenzylated catechin 13. After formylation through the classical Vilsmeier reaction, the obtained compound 14 was reduced by $\mathrm{LiAlH}_{4}$ giving the hydroxymethyl derivative $\mathbf{1 5}$. Further reduction of the latter gave the target product $\mathbf{1 6}$ with a good yield. The bromided adduct $\mathbf{1 7}$ was obtained from $\mathbf{1 3}$ by 
action of NBS. Gram-scale amounts of taxifolin (9) were prepared from (+)-catechin through reactions involving oxidation processes as previously described [17].

The structures of these modified catechin derivatives were determined through UV, MS and NMR spectroscopy. Structure elucidation of compound $\mathbf{1 6}$ will be detailed as example. The ESI-MS spectrum recorded in the positive ion mode showed signals located at $\mathrm{m} / \mathrm{z} 755,772$ and 777 corresponding to $[\mathrm{M}+\mathrm{H}]^{+},\left[\mathrm{M}+\mathrm{NH}_{4}\right]^{+}$and $[\mathrm{M}+\mathrm{Na}]^{+}$ions respectively and indicating a molecular weight of $754 \mathrm{amu}$ in agreement with the structure of compound 16. The usual characteristic flavan-3ol RDA fragmentation was also observed at $\mathrm{m} / \mathrm{z} 423$, [M+H-332 $]^{+}$ion, corresponding to the protonated A moiety (Figure 3).

Scheme 1. Synthesis pathways of the studied modified flavanol monomers.

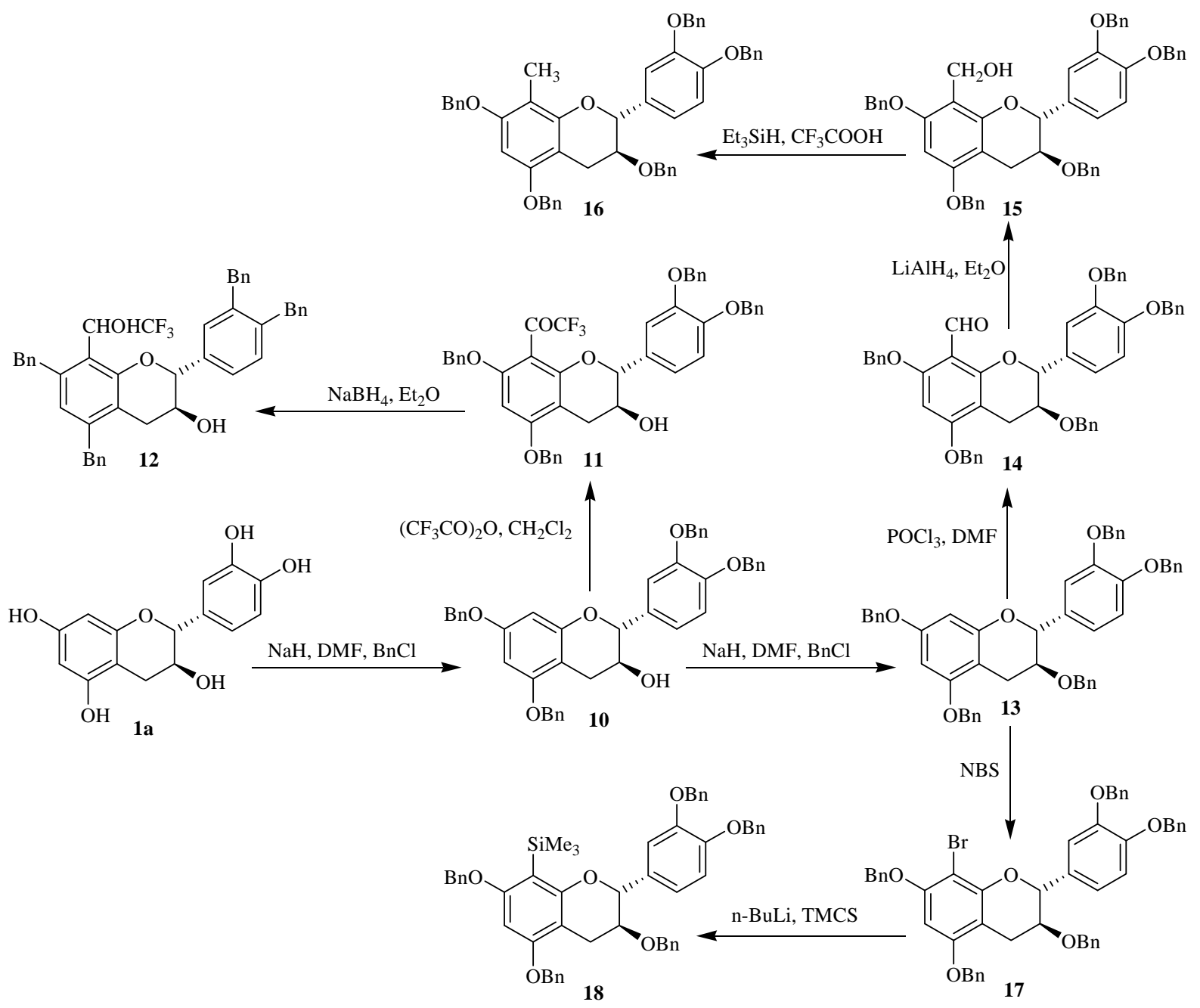


Figure 3. Main fragmentations observed in compounds $\mathbf{1 1}, \mathbf{1 6}$ and 18 and main ${ }^{1} \mathrm{H}-{ }^{13} \mathrm{C}$ long range correlations observed for compound $\mathbf{1 6 .}$

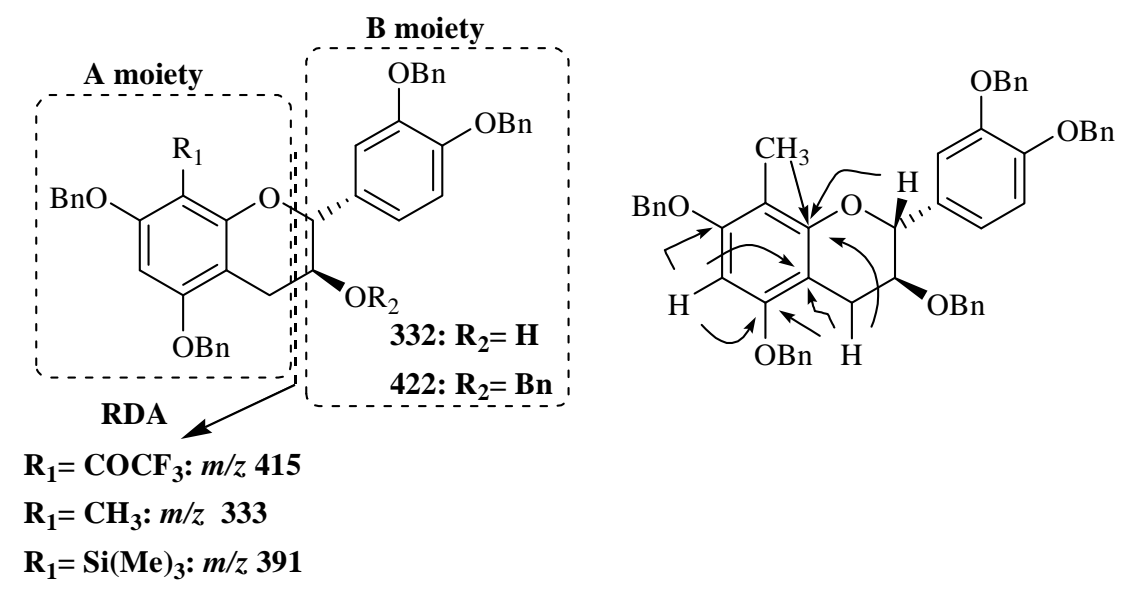

The remaining outstanding question that needed to be resolved was related to the position of the methyl group on the flavanol A ring. This constitutes the most encountered problem in flavanol structural characterization. Since the two positions 6 and 8 are almost magnetically equivalent, they could not be distinguished on the basis of their chemical shift. In our case, assuming that the substitution occurs at the more nucleophilic positions of the flavanol skeleton, i.e 6 or 8, as confirmed through ES-MS spectrometry, determination of the residual proton (H6 or H8) could not be achieved based only on its chemical shift but would rather requires the use of 2D NMR analysis. The position of the $\mathrm{CH}_{3}$ group on the aromatic $\mathrm{A}$ ring was elucidated by long range distance carbon-proton correlations established by 2D NMR HMBC experiments through the following reasoning. The usual pyran ring protons $\mathrm{H} 4$ [(2.7 ppm, $d d, J=16.7$ and $5.6 \mathrm{~Hz})$ and $3.0 \mathrm{ppm}(d d, J=16.7$ and $8.7 \mathrm{~Hz})], \mathrm{H} 3$ (6.6 ppm, $m$ ) and H2 (7.9 ppm, $d, J=8.0 \mathrm{~Hz}$ ) were easily assigned by ${ }^{1} \mathrm{H}-\mathrm{NMR}$ analysis. The three B ring protons were observed between 6.9 and $7.0 \mathrm{ppm}$. For the aromatic A ring, only one proton signal appearing as a singlet at $6.2 \mathrm{ppm}$ was present indicating a monosubstitution. The presence of the $\mathrm{CH}_{3}$ group was confirmed through ${ }^{1} \mathrm{H}$-NMR analysis showing a singulet at $2.1 \mathrm{ppm}$. The protonated carbon chemical shifts were assigned through NMR HSQC analysis.

The definitive structure elucidation of compound $\mathbf{1 6}$ was achieved by HMBC experiment which allowed assignment of all hydrogen and carbon atoms. In addition to their correlations with C2 (79.8 ppm) and C3 (75.0 ppm), H4 protons (2.8 and $3.0 \mathrm{ppm}$ ) correlated with 3 carbons located at 102.7, 153.1 and $154.8 \mathrm{ppm}$. Carbons C4a, C8a and C5 are in a favorable position to give such correlations (Figure 3). The signal observed at 102.7 ppm was attributed to C4a due to its chemical shift position compared to C8a and C5 which are linked to an oxygen atom. The carbon signal located at $153.1 \mathrm{ppm}$ also gave a correlation with $\mathrm{H} 2$, which pointed to the C8a carbon and thus the remaining signal observed at 154.8 ppm was attributed to C5. The C8a signal thus attributed did not show any correlation with the residual A ring aromatic protons which is thus H6. This was also confirmed by the presence of a correlation between $\mathrm{C} 5$ and the residual aromatic proton and between the methyl protons and the C8a (Figure 3). The position of the methyl group on the A ring 8 position was thus demonstrated. 


\section{Synthesis of activated flavanols}

Oxidation at the benzylic C-4 position of flavanols constitutes a fundamental step in proanthocyanidin synthesis giving $O$-alkylated adducts. The use of DDQ $[15,16]$ as oxidant of tetrabenzylated catechin $\mathbf{1 0}$ in presence of ethylene glycol gave the corresponding 4-O-alkylated catechin 19 with good yields attaining $70 \%$, as indicated in our previous work [14] (Scheme 2).

Scheme 2. Synthesis of the activated catechin derivatives.

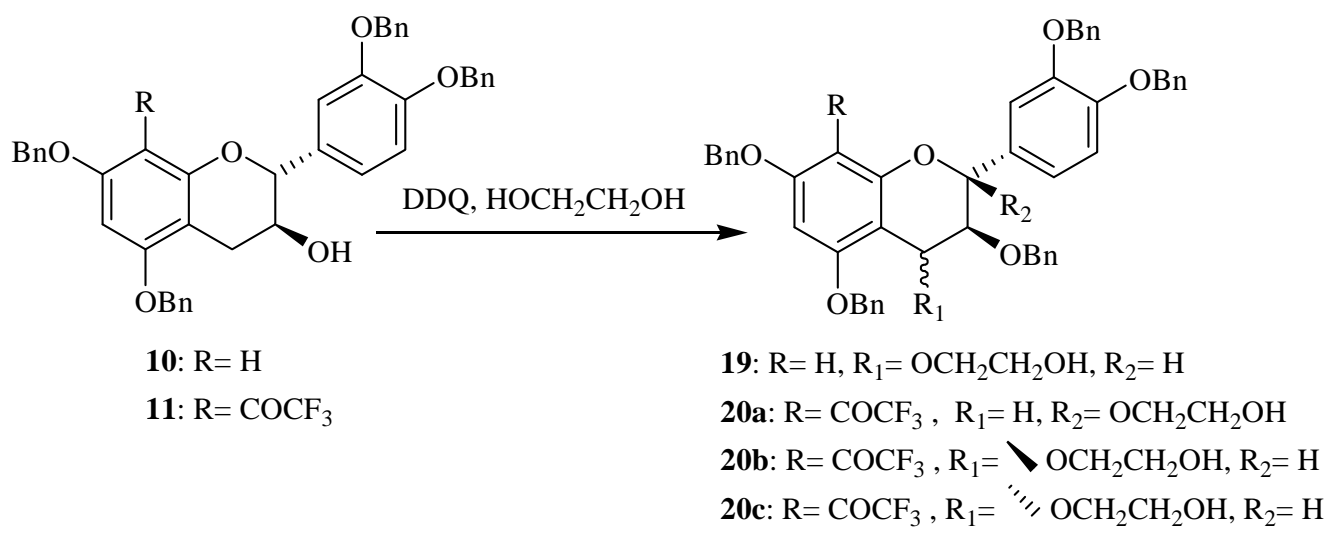

In order to investigate the use of other electrophiles in the proanthocyanidin synthesis, the oxidation of pentabenzylated catechin 13 with $\mathrm{DDQ} / \mathrm{CH}_{2} \mathrm{Cl}_{2}$ was conducted in presence of water (Scheme 3).

Scheme 3. Synthesis of 4-activated catechin through DDQ oxidation and in presence of $\mathrm{H}_{2} \mathrm{O}$.

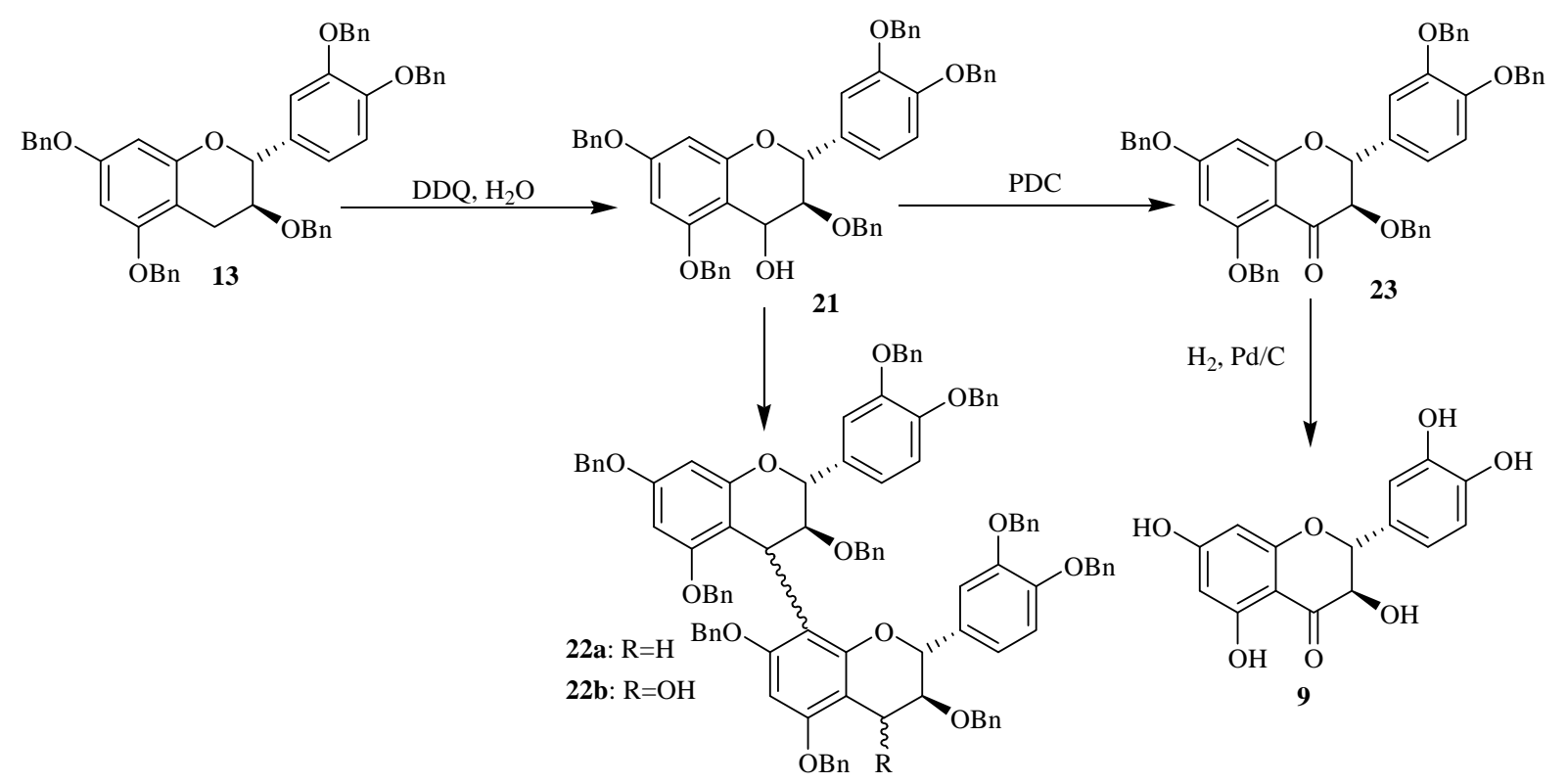

The flavan-3,4-diol 21 and the flavan-4-one 23 were obtained respectively in 66 and 15\% yield and their structures were confirmed by MS and NMR spectroscopy [17]. All the obtained data were in agreement with the structures proposed for these compounds. Moreover, the coupling constant for the 
AMX spin system of the C-ring protons $\left(J_{3,4}=3.6 \mathrm{~Hz}\right)$ of compound 21 indicated a 3,4-cis relative configuration for this ring, i.e a $4 \beta$-bond.

The flavan-4-one was probably formed by oxidation of the first formed flavan-3,4-diol 21. In addition, the formation of the dimeric compounds 22a (10 \%) and 22b (7 \%) was also detected through LC/ESI-MS analysis conducted in the positive ion mode. Compound 22a was detected by its $[\mathrm{M}+\mathrm{H}]^{+}$ ion located at $\mathrm{m} / \mathrm{z}$ 1479.7, corresponding to a dimeric structure consisting of two catechin units. Its formation involved probably the formation of a carbocation from compound $\mathbf{2 1}$ and its further reaction on a free benzylated catechin 13. Furthermore the 4-hydroxy oxidized form of compound 22a was also detected through LC/ESI-MS analysis in the positive ion mode. The mass spectrum of this compound noted 22b showed signals located at $\mathrm{m} / \mathrm{z}$ 1496, 1513 and 1518 corresponding respectively to [M+H] ${ }^{+}$, $\left[\mathrm{MNH}_{4}\right]^{+}$and $[\mathrm{MNa}]^{+}$in agreement with the (+)-catechin dimeric structure with an additional hydroxy group.

The mass spectrum of compound 22b showed several signals corresponding to the flavanol characteristic fragmentations. Its structure was finally confirmed through NMR analysis. The formation of this compound could be achieved through oxidation of compound 22a or by action of the carbocation generated from compound $\mathbf{2 1}$ and its further coupling with an already formed 4hydroxybenzylated catechin 21. The formation of such dimeric precursor showed that the oxidation through DDQ could also occur on more long chains and then could be considered as a pathway for the preparation of more oligomerized flavanol precursors.

The preparation of these 4-activated (+)-catechin derivatives was achieved in order to use them as nucleophiles for the synthesis of modified proanthocyanidins having a modified catechin as terminal units and a free $(+)$-catechin as upper unit. Within the scope of preparing proanthocyanidins with a modified catechin as upper units, we were interested in investigating the oxidation of the previously prepared 8-substituted catechins. The 8-trifluoroacetyl derivative of tetrabenzylated catechin 11 was used as starting material in this first assay and using DDQ as oxidation agent in presence of ethylene glycol (Scheme 2). No oxidation was observed in the conditions previously used on tetrabenzylated catechin. After optimization of the reaction conditions, the formation of three new compounds was observed. Their isolation was achieved through column chromatography and their structure elucidation was initiated through MS and NMR spectroscopy.

Mass spectral analysis of the three isolated compounds, conducted in the positive ion mode, showed signals located at $\mathrm{m} / \mathrm{z} 807,824,829$ and 845. These signals corresponded to $[\mathrm{M}+\mathrm{H}]^{+}$, $\left[\mathrm{M}+\mathrm{NH}_{4}\right]^{+},[\mathrm{M}+\mathrm{Na}]^{+}$and $[\mathrm{M}+\mathrm{K}]^{+}$, respectively, and indicating a molecular weight of $806 \mathrm{amu}$. This result is in agreement with structures consisting of a tetrabenzylated moiety linked to a hydroxyethoxy group meaning that oxidation reaction has occurred in presence of DDQ. Since the three MS and UV data supported the conclusion that the three structures consisted of flavan-3-ol units linked to a $\mathrm{HOCH}_{2} \mathrm{CH}_{2} \mathrm{O}$ group, the primary problem was the establishment of the alkoxy location. Even if the mass spectra of the three compounds indicated the same molecular ions, some differences were observed in their fragmentation pattern. Thus signal peaks at $\mathrm{m} / \mathrm{z} 393$ and 415 were observed for compound 20a, while 20b and 20c showed signals at $\mathrm{m} / \mathrm{z} 333$ and 475 suggesting different alkoxyl group locations for these compounds shown in Figure 4. 
Figure 4. Main fragmentations observed in compounds 20a, 20b and 20c.

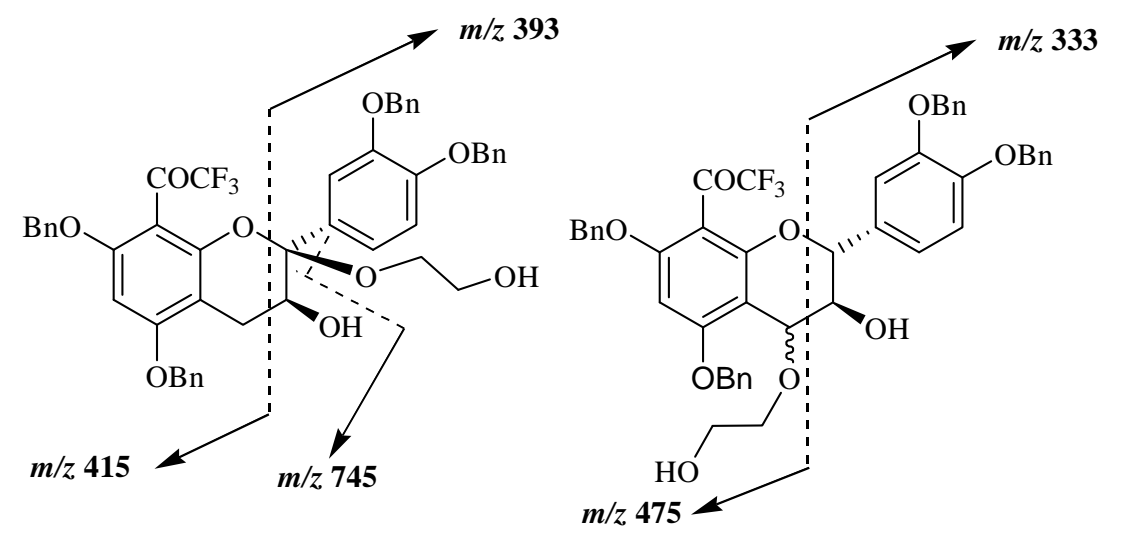

The position of the alkoxyl group was finally achieved through NMR analysis which easily indicated that the aromatic A proton in addition to those of the B ring were still present for the three compounds meaning that the oxidation occurred on the pyranic $C$ ring. In the case of compound 20a (10\%) the presence of the two double doublets characteristic of the two H4 protons was observed meaning that the oxidation occurred at the 2 position. This was confirmed through ${ }^{13} \mathrm{C}$ and DEPT NMR analysis, where only one singularily protonated carbon corresponding to C3 was observed. It must be noted that similar C2 oxidation product was already observed in the reaction involving DDQ oxidation of tetrabenzylated epicatechin in presence of methanol [29]. In the case of compounds 20b (55\%) and 20c (20\%) similar NMR spectra were obtained. In the ${ }^{1} \mathrm{H}$ spectrum the absence of the AMX characteristic signal of the two $\mathrm{H} 4$ protons was observed. This was also confirmed through ${ }^{13} \mathrm{C}$ and DEPT analysis showing that the two compounds were stereoisomers $R$ - and $S$-4-(2hydroxyethoxy) derivatives of the 8-trifluoroacetyl adduct of tetrabenzylated catechin. These compounds could then serve as monomer precursors for the preparation of modified proanthocyanidins with modified catechin upper unit.

\section{Lewis acid induced flavanol couplings}

Lewis acids have been employed in literature to synthesize proanthocyanidins. Thus $\mathrm{TiCl}_{4}, \mathrm{AgBF}_{4}$, $\mathrm{SnCl}_{4}$, TMSOTf have all been used to synthesize dimeric and oligomeric procyanidins of (+)-catechin and (-)-epicatechin units [29, 30-36]. In these reactions, the role of Lewis acids is to promote the formation of the benzylic carbocation at C4 of a flavanol subunit starting from a C4 hetero substituted flavanol, which thereafter undergoes a Friedel-Craft-like addition on a second flavanol subunit. For this study, the Lewis acid $\mathrm{TiCl}_{4}$ was used as a carbocation promoting agent from the 4-(2hydroxyethyloxy) flavan-3-ol 19. Coupling reaction between compound $\mathbf{1 1}$ and $\mathbf{1 9}$ in a 6/1 molar ratio was investigated in $\mathrm{CH}_{2} \mathrm{Cl}_{2}$ according to Scheme 4. The reaction was monitored by TLC and HPLC and showed the disappearance of compound $\mathbf{1 1}$ and appearance of new compounds. Among the products formed, compound $\mathbf{2 4}$ was obtained in sufficient amounts to allow its structure investigation. This was achieved through UV, LC/ESMS, ES CAD MS/MS and NMR analysis.

The UV spectrum of compound 24 exhibited similar maxima (285 and $305 \mathrm{~nm}$ ) to that of compound 11, indicating that the original flavan structure with the $\mathrm{COCF}_{3}$ group was retained. The 
mass spectrum obtained in the positive ion mode showed signals at $\mathrm{m} / \mathrm{z} 1395,1412,1417$ and 1433 corresponding respectively to $[\mathrm{M}+\mathrm{H}]^{+},\left[\mathrm{M}+\mathrm{NH}_{4}\right]^{+},[\mathrm{M}+\mathrm{Na}]^{+}$and $[\mathrm{M}+\mathrm{K}]^{+}$indicating a molecular weight of 1394 amu in agreement with a dimeric structure consisting of tetrabenzylated (+)-catechin 10 linked to its trifluoroacylated derivative 11. However, the remaining problem was the establishment of the position of linkage to compound $\mathbf{1 1}$, as the tetrabenzylated catechin moiety is linked through its 4 position.

Scheme 4. $\mathrm{TiCl}_{4}$-catalyzed flavanols coupling reactions.

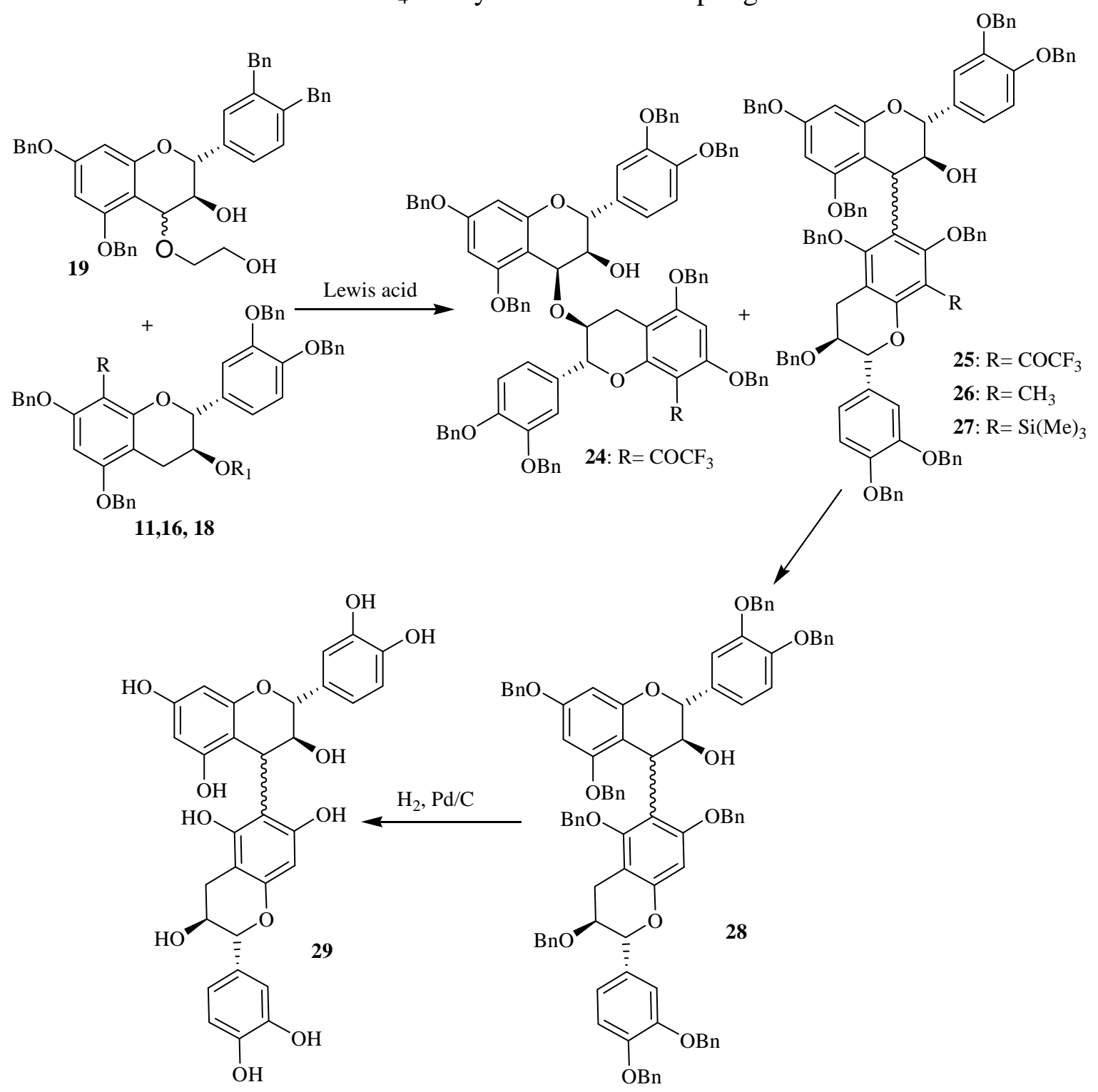

In addition to the signals indicated above, the mass spectrum of compound $\mathbf{2 4}$ also showed signals at $m / z 747$ and 649 corresponding to the fission of the bond between the two constitutive units. Among the other observed signals two of them were located at $\mathrm{m} / \mathrm{z} 1063$ and 981 and were also observed in the spectrum obtained through positive ES CAD MS/MS fragmentation of the signal located at $\mathrm{m} / \mathrm{z} 1395$ $\left([\mathrm{M}+\mathrm{H}]^{+}\right.$ion). The signal observed at $\mathrm{m} / \mathrm{z} 1063$ was attributed to the characteristic RDA fragmentation corresponding to the $[\mathrm{M}+\mathrm{H}-332]^{+}$ion as what was observed for compound $\mathbf{1 1}$ through a loss of the $\mathrm{B}$ moiety. The second fragmentation observed at $\mathrm{m} / \mathrm{z} 981$ correspond in fact to the $[\mathrm{M}+\mathrm{H}-414]^{+}$ion, meaning a loss of the A moiety of compound $\mathbf{1 1}$ unit (Figure 5) and corresponding to another RDA 
fragmentation. The occurrence of this fission indicated the presence of the A moiety in the structure of compound 24. In other words, this means that the isolated compound is not a C4 $\rightarrow$ C6 dimer since only one RDA fragmentation corresponding to the $[\mathrm{M}+\mathrm{H}-332]^{+}$ion could be possible in this case. The possible linkage is thus expected to occur via the 2 or 3 position of the F ring or possibly the 2', 5' or 6’ positions of the ring $\mathrm{E}$.

Figure 5. Main fragmentations observed and main ${ }^{1} \mathrm{H}^{-13} \mathrm{C}$ long range correlations observed in compound 24.
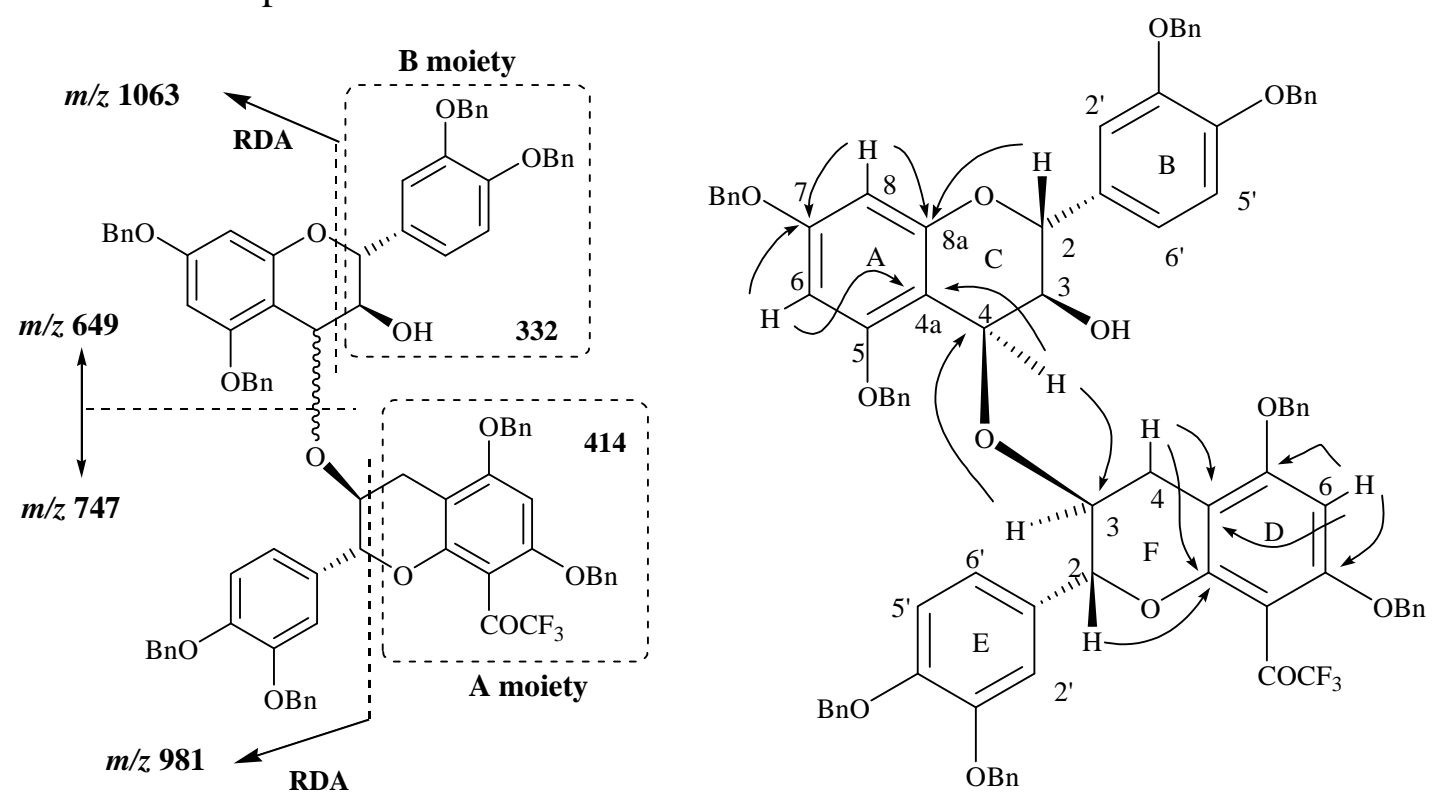

Through NMR analysis and in conjunction with the absence of a doubly benzylic methylene proton characteristic of a $\mathrm{C} 4 \rightarrow \mathrm{C} 6$ linkage and taking into account the dimeric structure of the compound as supported by MS analysis, the NMR data collectively indicated a dimeric structure with an interflavanyl ether bond connecting the two heterocyclic $\mathrm{C}$ and F rings. Taking into account the fact that the linkage did not involve the H2, H3, H4 F ring protons since they were all evidenced through NMR analysis, a (4-O-3) mode of linkage was thus concluded to occur between the two flavan-3-ols units. This was also confirmed by comparison of the chemical shifts of the $\mathrm{H} 4$ and $\mathrm{H} 3$ resonances of both the $\mathrm{C}$ and the $\mathrm{F}$ rings with those of their precursors. Finally the structure of compound was univocally confirmed through HMBC analysis where several long range correlations were observed. In particular correlations involving proton and carbon of both $\mathrm{C}$ and $\mathrm{F}$ rings via the oxygen atom were observed and confirmed thus the ether linkage involved in compound 24. Full assignment of the protons and carbon chemical shifts was achieved through HMBC analysis (Figure 5) where the main correlations involving $\mathrm{H} / \mathrm{C}$ of the $\mathrm{C}$ and $\mathrm{F}$ rings were showed in agreement with the proposed structure.

It was concluded that a (4-O-3) linkage was occurred between the two flavan-3-ol units. Moreover, coupling constants for the AMX spin system of the C-ring protons $\left(J_{3,4}=3.2 \mathrm{~Hz}\right)$ indicated a 3,4-cis relative configuration for this ring, which was determined through homonuclear decoupling experiment. The complete stereoselectivity of the reaction remains, however, to be explained and should presumably be due to a participation of the hydroxy group at C3 of 11. However, its involvement in the stereochemical course of the reaction cannot be, in our case, related to the formation of a protonated epoxide similar to that reported by Bennie et al. [37] in a work dealing with the dimerization of epioritin-4-ol derivatives. 
Figure 6. Extracted ion chromatogram recorded at $\mathrm{m} / \mathrm{z} 1395$ and main fragmentations observed in compound 25.

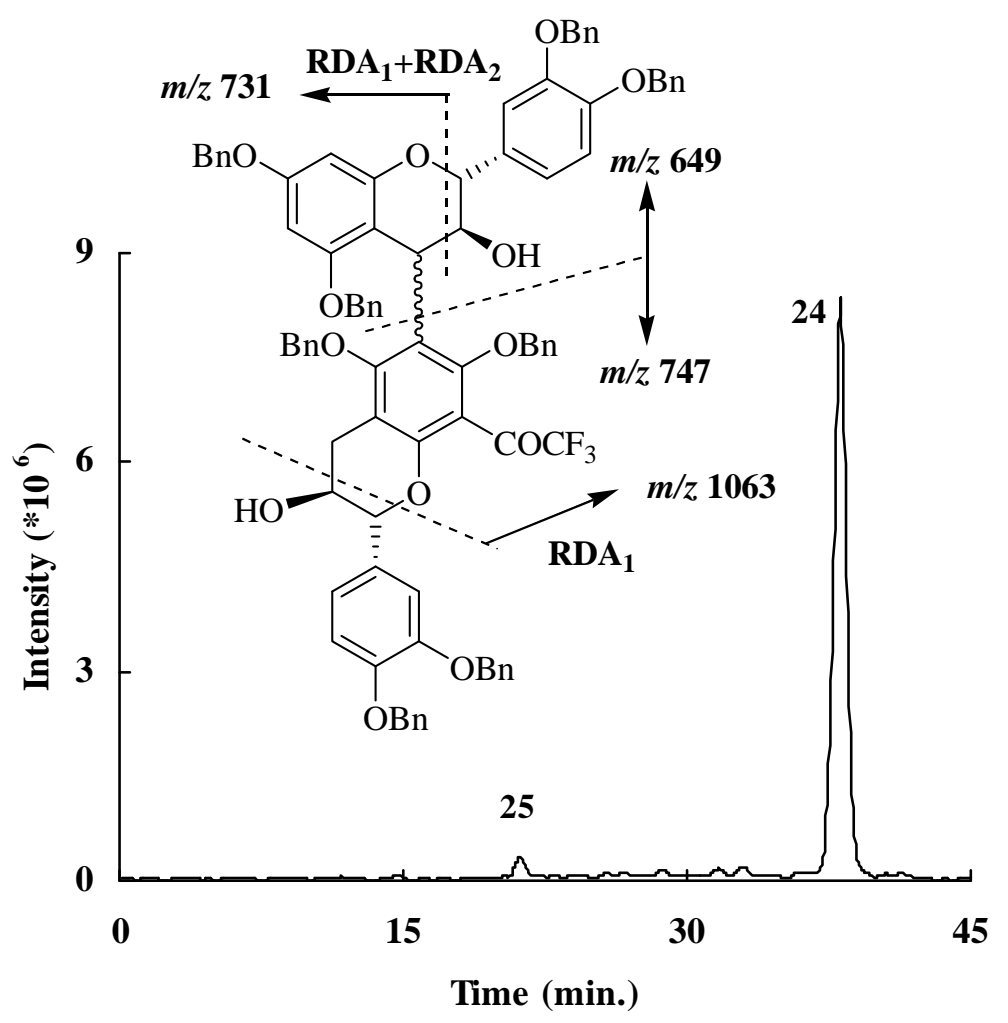

In order to verify the presence of other dimeric structures the mixture was explored by HPLC coupled to a mass spectrometry detection operating in the positive ion mode. An extracted ion current chromatogram recorded at $\mathrm{m} / \mathrm{z} 1395$ and 1412 (Figure 6) and corresponding to a dimeric structure molecular weight showed the presence, in addition to compound $\mathbf{2 4}$, of a minor compound, which is possibly the carbon-carbon coupled dimer 25. The fragmentations observed for compound $\mathbf{2 5}$ were in agreement with the proposed dimeric structure consisting of tetrabenzylated $(+)$-catechin $\mathbf{1 0}$ coupled to its trifluroacylated derivative $\mathbf{1 1}$ through a C4 $\rightarrow$ C6 linkage (Figure 6).

The almost exclusive, high yielding formation under these conditions of the novel ether-linked procyanidins as main compound rather than its carbon-carbon $\mathrm{C} 4 \rightarrow \mathrm{C} 6$ coupled analogue reflects the importance of electronic features in the formation of flavan-3-ol dimers. The poor nucleophilicity of the A ring monomeric precursor, caused by the presence of the $\mathrm{COCF}_{3}$ group, permits alternative centers to participate in the interflavanyl bond formation.

The obtained results discussed above showed that the interflavanic carbon-carbon linkage formation was largely inhibited during Lewis acid induced flavanols coupling reactions by the presence of an electron-withdrawing group, while this was not the case with an electron-donor group like the methyl substituent. This could constitute thus a setereoselective method for the formation of C4 $\rightarrow$ C6 procyanidin dimers which are usually obtained as minor compounds the C4 $\rightarrow$ C8 ones. In order to apply this technique to the stereoselective preparation of natural dimeric procyanidin of the C4 $\rightarrow$ C6 type, we unsuccefully tried to remove the methyl group from the modified derivatives 26. Then we used the trimethylsilyl group which is easily removable by hydrolysis. Indeed, during purification of compound $\mathbf{1 8}$ on silicagel chromatography column, we saw that this compound was 
easily transformed to $\mathbf{1 0}$ by loss of the $\mathbf{8}$ substituent group. This prompted us to use this compound as nucleophile acceptor unit in the Lewis acid coupling reaction. The reaction was monitored through TLC and LC-MS, showing the presence of compound with a molecular mass of 1460 amu corresponding to the dimeric compound 27. After hydrolysis and hydrogenolysis, the corresponding product 29 was separated and analyzed through mass spectroscopy. The obtained results indicated a molecular mass of $578 \mathrm{amu}$ in agreement with the dimeric structure of compounds 29. Indeed, the mass spectrum of compound $\mathbf{2 9}$ showed procyanidin characteristic RDA fragmentation giving an ion fragment by a loss of 152 mass units. We tried to proof the interfalvanic linkage of the obtained compound through 2D NMR technique, but due to degradation of the obtained compound, our attempt was unsuccessful.

Flavanol coupling through condensation with cat+ carbocation arising from taxifolin

After having investigated the Lewis-acid induced flavanol coupling reaction involving 4-activated catechin derivatives, we were interested to use other precursors. The first experiments were achieved using taxifolin (9), a natural product often used as starting material in the hemisynthesis of procyanidins [36,38] or anthocyanin-tannin adducts [39]. This compound was prepared as previously described [17] and was used in this work as precursor of the electrophilic unit by action of $\mathrm{NaBH}_{4}$ giving a 4-hydroxy group which releases a 4-carbocation adduct in a mildly acidified medium. The compounds $\mathbf{5}$ and $\mathbf{7}$ were used in their free form as nucleophilic units and the reactions were studied through LC-MS techniques (Scheme 5).

Scheme 5. Flavan-3-ol coupling reactions using taxifolin (9) as starting material.

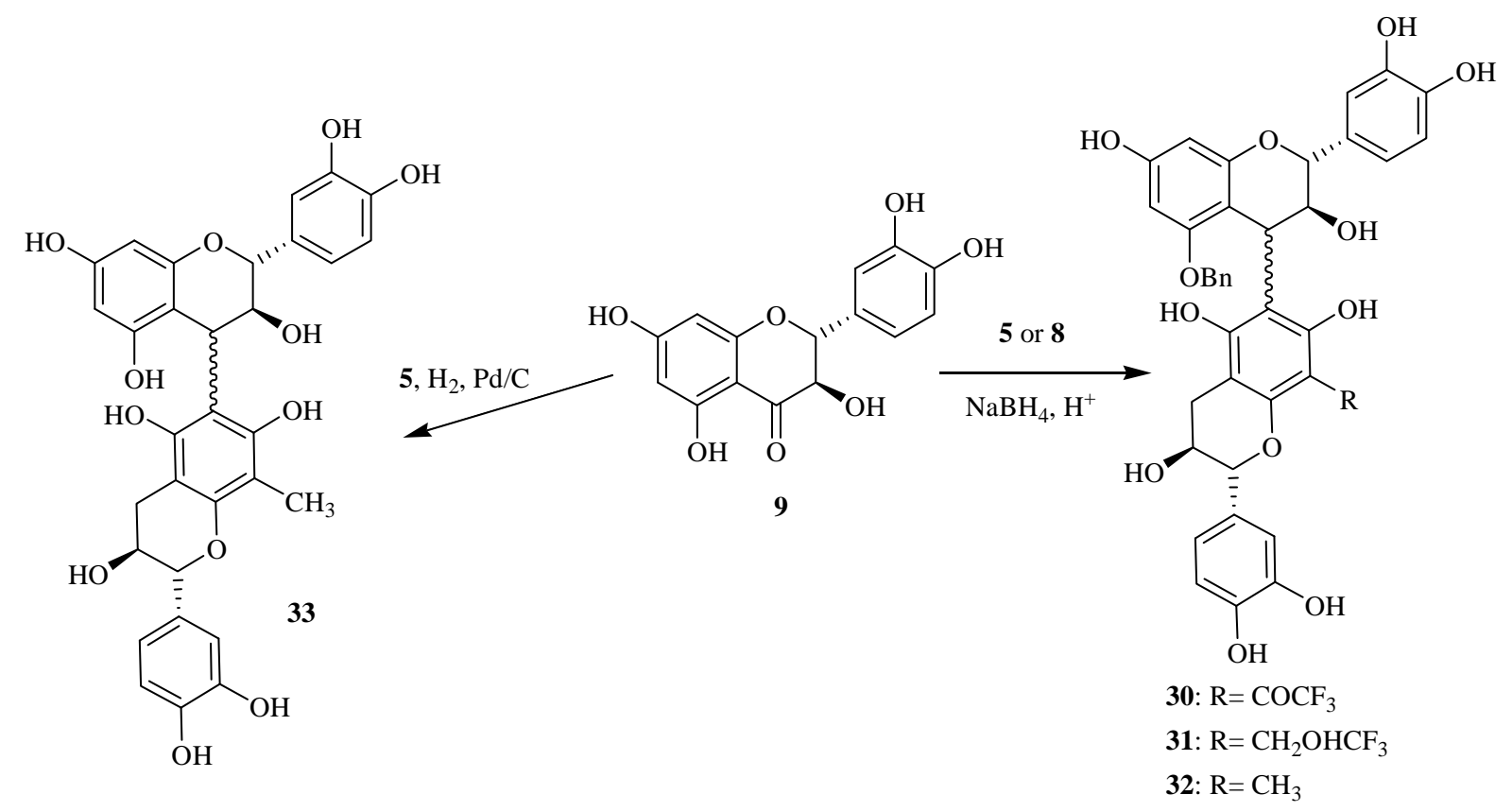

When the reaction was assayed with compound $\mathbf{8}$, new compounds showing a mass signals at $m / z$ 673 and 675 in the negative ion mode were detected. These compounds were interpreted as the dimeric modified procyanidins $\mathbf{3 0}$ and $\mathbf{3 1}$, formed by action of the carbocation cat + on the 8-substituted 
catechin compounds used as nucleophile units. The cat+ unit is issued from the reduction of taxifolin into a flavan-3,4-diol, followed by protonation and dehydration. The action on compound $\mathbf{8}$ gave thus the dimer 30 while compound $\mathbf{3 1}$ was formed after reduction of the carbonyl group by $\mathrm{NaBH}_{4}$ and further action of the cat+ adduct. This was confirmed by detection of compound giving a signal peak at $\mathrm{m} / \mathrm{z} 591$ corresponding to the reduced 8-substituted monomer. The same reaction was investigated using the 5 monomer and the corresponding methylated dimer 32 was detected through LC-MS analysis.

\section{$\mathrm{H}_{2} /$ Pd catalyzed flavanol coupling}

Another protocol for the preparation of procyanidin was adapted from the methylene linked flavanol dimers synthesis recently described [16]. The application of such reaction to procyanidin synthesis was achieved through hydrogenation of taxifolin (9) in the presence of an excess of the methylated catechin 5 used as nucleophile (Scheme 5). The reaction was explored through LC-MS analysis and the formation of new compounds initially absent in the mixture was observed. Among the obtained products, compound with a molecular mass of 592 amu corresponding to the dimeric procyanidin 33 was observed. The mass spectrum of compound 33 recorded in the negative ion mode showed a molecular ion at m/z 591 and characteristic fragment signals as shown in Figure 7.

Figure 7. Mass spectrum and main fragmentations observed in compound 33.

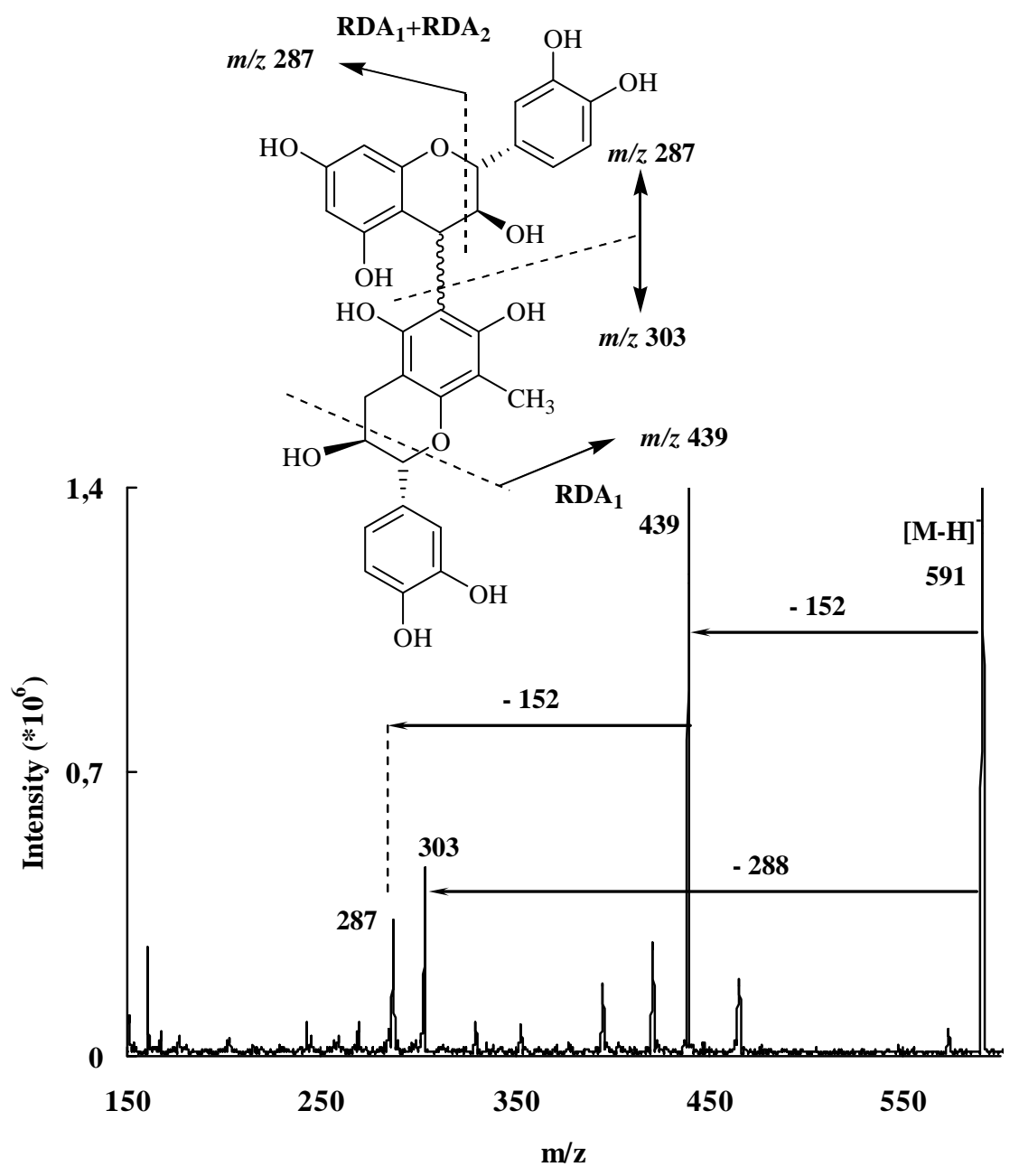


Trametes versicolor laccase induced oxidation of flavonoids

Although a number of papers in the literature have already discussed the enzymatic oxidation of flavonols, most of them only reported the kinetic features of the reaction measured through the changes of UV absorption. Few have tried to look at the precise structure of the oxidized products and the mechanistic pathway(s) of their formation. Moreover, the main reports have focused only on the enzymatic oxidation of quercetin and quercetin glycosides. In order to allow chemical mechanism determination for this type of reaction, we decided to test our enzymatic system on several commercially available flavonols regarding their substitution either on B or C rings. Indeed, most of the already published studies on flavonol have underlined the predominance of $\mathrm{B}$ ring oxidation, as laccases are essentially reported to have a phenol or catechol oxidase activity giving rise in most cases either to oxidized monomeric species or oligomeric compounds obtained through radical-radical couplings [40].

The choice of the starting materials (Figure 8) was made on account of several results published in the literature on the structure-antioxidant activity relationships of flavonoids. It has indeed been clearly established that the B-ring is the most important site for H-transfer and consequently antioxidant capacity. In contrast, the A-ring seems to be less important. On the other hand, the 2-3 double bond should also contribute to the antioxidant activity, as it ensures $\pi$-electron delocalization between the Band C-rings, which contributes to the stabilization of the radicals $\mathrm{RO}^{\circ}$ formed in the oxidation process after $\mathrm{H}$ atom abstract [41]. Moreover, an important issue that is still under debate is the role of the 3$\mathrm{OH}$ group. In vitro studies demonstrated that this hydroxy group contributes to the antioxidant potential. Indeed, blocking the $3-\mathrm{OH}$ group as in rutin or removing it as in luteolin significantly decreases the activity [42]. The influence of the 3-OH group has also been proven during the metabolization of quercetin [43], since quercetin is believed to coordinate to the copper containing active site of the 2,3-dioxygenase issued from human intestinal bacteria through the 3-OH and the carbonyl group at C4, allowing $\mathrm{H}$ abstraction and oxidation at C2 [44].

An important feature of our study compared to those already published is the use of a laccase as enzymatic oxidant. Indeed, other studies most often reported the oxidation of flavonoids either with chemical radical initiators like DPPH or enzymatic system like PPO (polyphenol oxidase; in this case, the flavonoids are not the primary substrate of the enzyme, the oxidation being mediated by the oquinone from caffeoyl quinic acid). Therefore, in these two cases, oxidation of the flavonols may occur through either a mono- or a di-electronic transfer (Figure 9).

The possibility of a di-electronic transfer may indeed favor the oxidation of diphenol through formation of semiquinones and quinones, and the thermodynamic of the reaction would thereby be directed by the stability of the potentially formed products rather than by the stability of the radicals formed through $\mathrm{H}$-abstraction. In the case of a laccase, albeit the complete mechanisms of the reaction, and mainly the pathway leading to oxygen reduction is not clearly determined [45], the monoelectronic transfer is the more privileged mechanism, therefore allowing to investigate the stability and the reactivity of the various $\mathrm{RO}^{\circ}$ potentially formed as primary product of the oxidation since quinones may only be the result of radical dismutation, kinetic of which would probably not be competitive with this of a radical coupling reaction. Indeed, upon the four copper atoms contained in the structure of the 
laccase, only one is involved in the oxidation of the substrates, the three other atoms being responsible for the oxygen reduction and oxidation of the $\mathrm{Cu}(\mathrm{I})$ atom of the active site of the enzyme.

Figure 8. Structures of the flavonoids studied in the enzymatic oxidation. The structures of the obtained oxidized compounds are also shown.<smiles>[R]c1ccc(-c2cc(=O)c3c(O)cc(O)cc3o2)cc1[R]</smiles>

34: $\mathrm{R}=\mathrm{H}$

35: $\mathrm{R}=\mathrm{OH}$<smiles>[R]c1cc(C(=O)C2(O)Oc3cc(O)cc(O)c3C2=O)ccc1O</smiles>

40: $\mathrm{R}=\mathrm{H}$

44: $\mathrm{R}=\mathrm{OH}$<smiles>[R]c1cc(-c2oc3cc(O)cc(O)c3c(=O)c2O)cc([R2])c1O</smiles>

36: $\mathrm{R}_{1}=\mathrm{R}_{2}=\mathrm{H}$

37: $\mathrm{R}_{1}=\mathrm{OH}, \mathrm{R}_{2}=\mathrm{H}$

38: $\mathrm{R}_{1}=\mathrm{R}_{2}=\mathrm{OH}$<smiles>[R]c1cc(C2(O)Oc3cc(O)cc(O)c3C(=O)C2(O)O)ccc1O</smiles>

41: $\mathrm{R}=\mathrm{H}$<smiles>O=C1C(=O)C(O)(c2cc(O)c(O)c(O)c2-c2c(-c3oc4cc(O)cc(O)c4c(=O)c3O)cc(O)c(O)c2O)Oc2cc(O)cc(O)c21</smiles>

47<smiles>[R]c1cc(C2(O)Oc3cc(O)cc(O)c3C(=O)C2=O)ccc1O</smiles>

39: $\mathrm{R}=\mathrm{H}$

43: $\mathrm{R}=\mathrm{OH}$<smiles>[R]OC1(c2ccc(O)c([R1])c2)Oc2cc(O)cc(O)c2C(=O)C1(O)O</smiles>

42a: $\mathrm{R}=\mathrm{Me}, \mathrm{R}_{1}=\mathrm{H}$

42b: $\mathrm{R}=\mathrm{Et}, \mathrm{R}_{1}=\mathrm{H}$

45a: $\mathrm{R}=\mathrm{Me}, \mathrm{R}_{1}=\mathrm{OH}$

45b: $\mathrm{R}=\mathrm{Et}, \mathrm{R}_{1}=\mathrm{OH}$

46: $\mathrm{R}=36, \mathrm{R}_{1}=\mathrm{OH}$

The first feature arising from our study was the non-oxidation of both 34 and 35, thereby confirming the crucial role of the 3-OH group in the oxidation process. Moreover, this first result also showed that the presence of an highly reactive catechol type B-ring is not sufficient to allow a oneelectron oxidative process to occur, also reflecting the postulated important role (DFT study) [46,47] played by the hydroxy group at C3 in the first steps of oxidation of flavonols.

Turning thereafter to the enzymatic oxidation of flavonols 36 and 37 , we were not surprised to observe that these two compounds, although not exhibiting the same hydroxylation pattern on the Bring, presented similar behaviours in our oxidation conditions. Indeed, the reaction mixture was 
reflecting in both cases the presence of only few compounds, MS analysis of which showed that the major ones were isomeric products corresponding to the addition of one oxygen atom $(\mathrm{M}+16)$.

Figure 9. General oxidation pathways for flavonols.

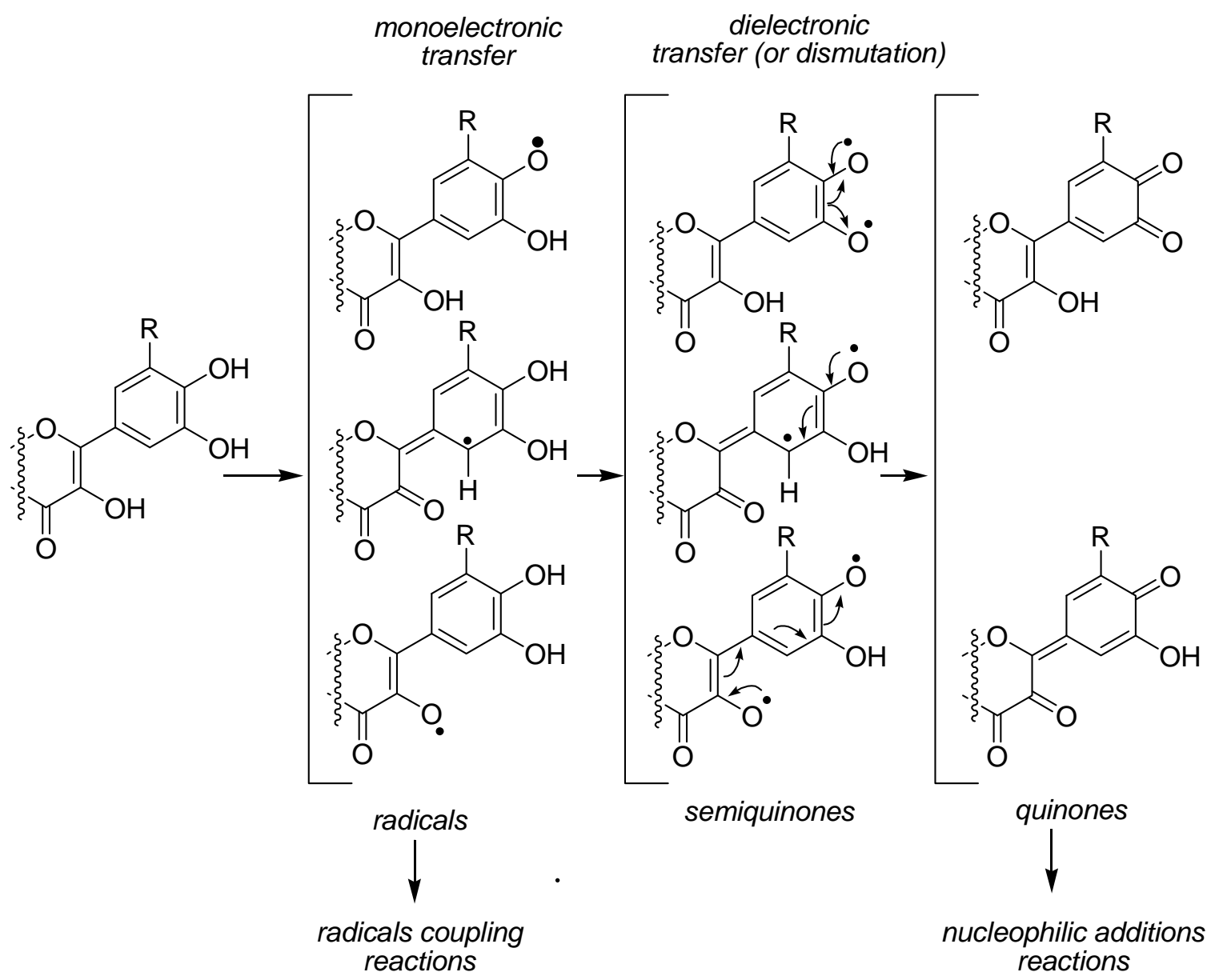

Depending on the solvent used for the reaction, the other products of the reactions were thereafter shown to be either dimeric compounds in aprotic conditions (acetonitrile) or products resulting from solvent addition in protic media $(\mathrm{MeOH}$ or $\mathrm{EtOH})$. In this latter case, turning from methanol to ethanol was the key step allowing to unambiguously underline this solvent addition. Later, NMR analysis confirmed the structure of compounds 39-42 and 42-45 as oxidation products of kaempferol and quercetin respectively, structure of which have already been more or less described in the literature $[48,49]$.

As an example, NMR spectra of $\mathbf{4 5 a}$ were used to determine its structure as follows. The ${ }^{1} \mathrm{H}-\mathrm{NMR}$ spectrum exhibited the same resonance pattern for the aromatic protons than quercetin but also showed a supplementary resonance at $3.1 \mathrm{ppm}$, integrating for 3 protons in accordance with the presence of a methyl group attached to an oxygen atom. The ${ }^{13} \mathrm{C}-\mathrm{NMR}$ spectrum was also quite similar to quercetin's, with two quaternary $\mathrm{sp}^{2}$ carbon resonances less, which were replaced by two resonances at 91.7 and $100.9 \mathrm{ppm}$. HSQC and HMBC experiments were thereafter performed and allowed the complete assignment of all carbon resonances. Indeed, HMBC correlation were observed for the resonance at $100.9 \mathrm{ppm}$ with protons of the methyl group as well as with protons H2', H5' and H6'. In 
the same time no HMBC correlations (Figure 10) were observed for carbon resonance at 91.7, which thereby was attributed to $\mathrm{C} 3$ when the resonance at $100.9 \mathrm{ppm}$ was assigned to $\mathrm{C} 2$, confirming the introduction of a methoxy group at C2 through trapping of the C2 radical. These results confirmed the possibility of enzymatic oxidation at $\mathrm{C} 2$ through activation of the $3-\mathrm{OH}$ group in a monoelectronic transfer process.

Figure 10. HMBC correlations observed for compound 45a.

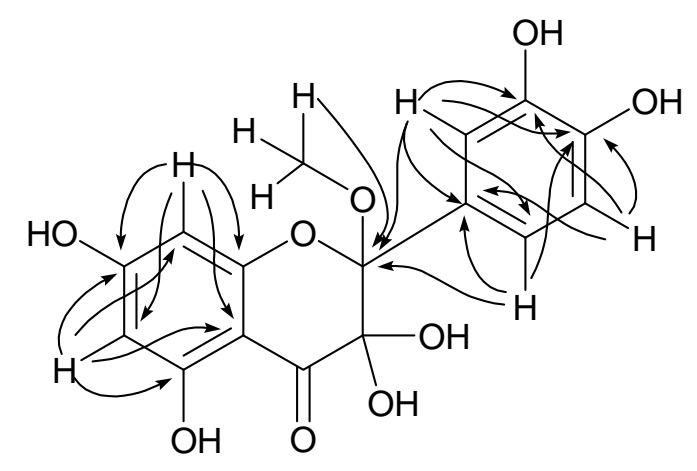

The structure of the dimeric compounds obtained through oxidation of these flavonols in acetonitrile was however more difficult to establish because of their low abundance in the reaction mixture which did not allow us to get them in sufficient amount for NMR spectroscopy. However, kaempferol oxidation led to the formation of only one dimeric compound ( $\mathrm{m} / \mathrm{z}$ 604) when quercetin allowed formation of two pseudo dimeric compounds at $\mathrm{m} / \mathrm{z} 498$ and 618. Carefull examination of the MS spectra of compounds at $m / z 604$ (46) and 618 (48), obtained from 36 and 37 respectively however reflected a behavioural discrepancy between these two flavonols. Indeed, when the formation of $\mathbf{4 8}$ is compatible with the formation of either a carbon-carbon or a carbon-oxygen single bond between the two monomeric subunits, formation of $\mathbf{4 6}$ is clearly not compatible with the formation of a carboncarbon bond between two oxidized subunits but rather to the formation of a carbon-oxygen bond through intermolecular trapping of the C-2 radical formed in the first step of the oxidation by an hydroxy group of another flavanol molecule in a similar way as this observed for the formation of oxidized monomers 42a,b (Scheme 6).

This assumption is also supported by the observation in the MS spectrum of $\mathbf{4 6}$ of a major fragment at $\mathrm{m} / \mathrm{z} 302$ also observed in compounds 42a,b, as a result of the easy cleavage of the OR bond. Unfortunately, we did not get sufficient data to determine which of the oxygen atom of kaempferol could be involved in this interflavanyl link. On the other hand, MS spectrum of $\mathbf{4 8}$ did not reveal similar fragmentations (no corresponding fragment at $\mathrm{m} / \mathrm{z} 318$ ) but rather those compatible with the classical fragmentations of the flavan skeleton. This may indicate a carbon-carbon single bond between both quercetin subunits, although we were unable to get sufficient data for a complete structure assignment. Compound at $\mathrm{m} / \mathrm{z} 498$, structure of which has also not been established, since it remains a very minor product of the reaction, should arise from a degradation of pseudo dimer $\mathbf{4 8}$. 
Scheme 6. Postulated oxidation mechanism for compounds $\mathbf{3 6}$ and $\mathbf{3 7 .}$<smiles>[R]c1cc(-c2c(-c3cc([R])c(OC)c(-c4oc5cc(O)cc(O)c5c(=O)c4-c4ccc(O)c([R])c4)c3O)oc3cc(O)cc(O)c3c2=O)ccc1O</smiles><smiles>[R]c1cc(-c2oc3cc(O)cc(O)c3c(=O)c2O)ccc1O</smiles>

We thereafter turned to the investigation of the possible oxidation of myricetin (38) by our enzymatic system. Albeit being already assumed as substrate of oxidase enzymes [50], oxidation products of myricetin have, to our knowledge never been investigated. As for $\mathbf{3 6}$ and 37, three solvents (methanol, ethanol and acetonitrile) were used in order to see the influence of the solvent in this reaction and to be potentially able to trap the C2 radical in protic media. However in this case, we unexpectedly observed no formation of C2 oxidized monomers. Indeed, although not exhibiting exactly the same chromatographic profile, the reaction mixtures in these three solvents essentially showed the presence of dimers and oxidized dimers at $m / z 634$ (2M-2H), 648, 650, 664, 666 and 684. Beside these compounds, oxidation conducted in protic media also exhibited some degraded dimers at $\mathrm{m} / \mathrm{z} 484$ and 620. Focusing our interest on the "pure" dimer at $\mathrm{m} / \mathrm{z} 634$, we were able to isolate it as a pure compound and its very simple ${ }^{1} \mathrm{H}$ NMR spectrum, due to symmetry, (Figure 11) allowed us to assign structure $\mathbf{4 9}$ to this compound, thus resulting from the coupling of two $\mathbf{B}^{\mathbf{3}}$ radicals (Scheme 7).

Figure 11. ${ }^{1} \mathrm{H}-\mathrm{NMR}$ spectrum of $\mathbf{4 9}$ (exchangeable protons are not shown).

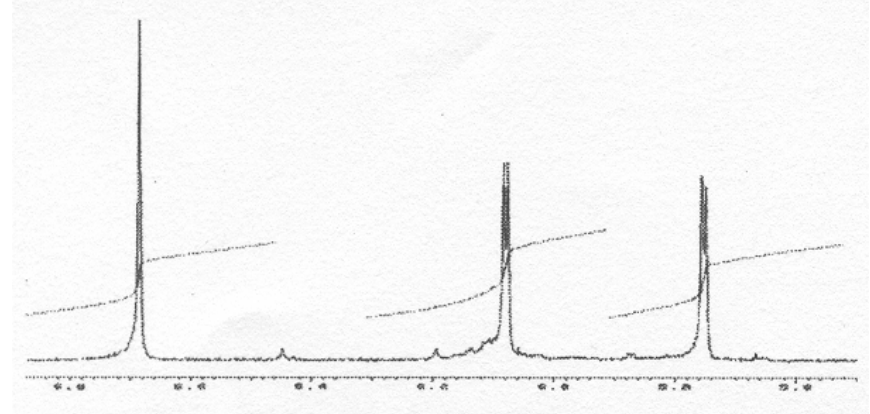


Scheme 7. Postulated oxidation mechanism for compound 38.

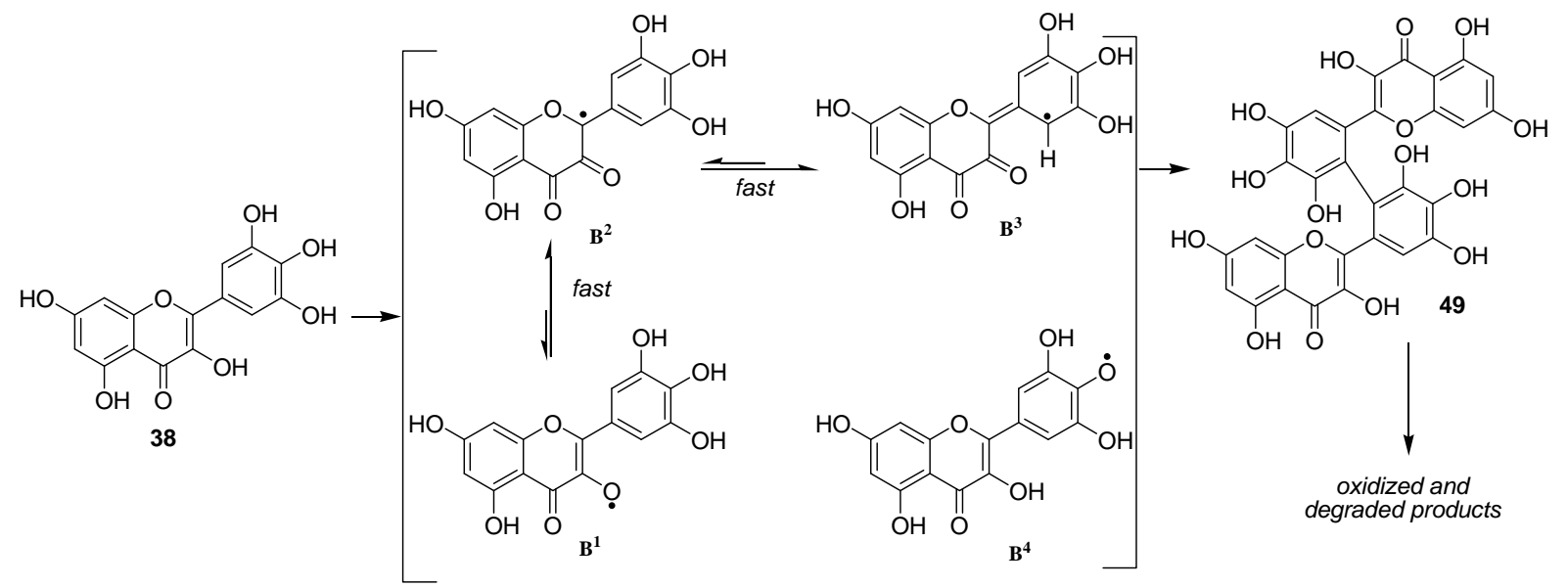

The most important feature arising from this reaction is the fact that no other type of linkages than this occurring in $\mathbf{4 9}$ was observed in all the other dimeric oxidation products. Indeed, when performing the enzymatic oxidation with $\mathbf{4 9}$ as starting material, the chromatographic profile of the reaction (Figure 12a), although not being completely similar from a quantitative point of view to that observed in the oxidation of $\mathbf{3 8}$ (Figure 12b), qualitatively showed the presence of the same oxidized dimers.

Moreover, the evolution of the chromatographic profile of the enzymatic oxidation of $\mathbf{3 8}$ clearly showed that $\mathbf{4 9}$ is first accumulated in the reaction mixture and then transformed into the other compounds and mainly into the compound exhibiting a molecular weight of 650 amu corresponding to a further oxidation with incorporation of an oxygen atom. According to the structure of the oxidation products of quercetin, structure $\mathbf{4 7}$ could be putatively assigned to this compound.

Figure 12. Chromatographic profiles of the oxidation reaction mixture at 3 hours of $\mathbf{3 8}$ (a) and 49 (b).

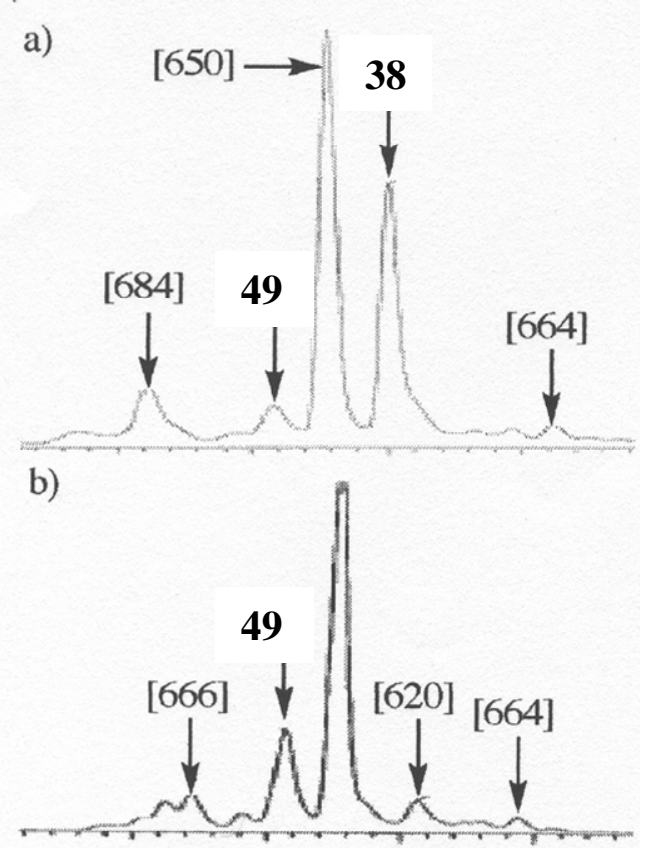


From a mechanistic point of view, our results showed that the oxidation of flavonols occurs first at $\mathrm{C} 2$ through abstraction of the enolic proton at $3-\mathrm{OH}$ and that, thereafter, the equilibrium between the possible isomeric radicals is directed by the substitution pattern of ring B. In the case of $\mathbf{3 6}$ and $\mathbf{3 7}$, radicals $\mathbf{A}^{3}$ and $\mathbf{A}^{4}$ are not sufficiently stabilized to allow the significative formation of dimeric compounds linked through a carbon-carbon biphenyl bond ( $\mathbf{A}^{3}-\mathbf{A}^{\mathbf{3}}$ radical coupling). On the other hand, in the case of myricetin $\mathbf{3 8}$, although the first formation of $\mathbf{B}^{4}$ radical could not be excluded, the most probable pathway remains the first formation of the $\mathbf{B}^{\mathbf{1}}$ radical, which rapidly isomerizes into the $\mathbf{B}^{3}$ one, which is stabilized by the presence of the three phenolic groups, leading to the formation of $\mathbf{4 9}$.

However, the presence of compounds resulting of further oxidation of this first formed dimer as well as the no observation of higher order oligomers, indicates that in dimeric compounds, oxidation thereafter occurs mainly at C-2. Moreover, the observation of compounds at $m / z 664,666$ and 684 , clearly demonstrates that compound $\mathbf{4 9}$ may undergo at least three further consecutive oxidations, thereby underlining the high antioxidant capacity of $\mathbf{3 8}$.

\section{Antioxidative activity of the synthesized compounds}

Free radicals are known to be a major factor in biological damages, and $\mathrm{DPPH}^{\bullet}$ has been used to evaluate the free radical-scavenging activity of natural antioxidants [51]. $\mathrm{DPPH}^{\circ}$, which is a molecule containing a stable free radical with a purple color, changes into a stable compound with a yellow color by reacting with an antioxidant which can donate an electron to DPPH'. In such case, the purple color typical of the free $\mathrm{DPPH}^{*}$ radical decays, a change which can be followed either spectrophotometrically $(517 \mathrm{~nm})$ or by detecting changes in concentration of starting materials and/or end reaction products, using HPLC analysis [52].

The fact that the extent of the reaction depends on the hydrogen donating ability of the antioxidant [53] make of it an indication of the capacity of the tested products to scavenge free radicals. This simple test can provide information on the ability of a compound to donate an electron, the number of electrons a given molecule can donate and on the mechanism of antioxidant action. In cases where the structure of the electron donor is not known (e.g. a plant extract), this method can afford data on the reduction potential of unknown materials. The $\mathrm{DPPH}^{\bullet}$ test is a very convenient method for screening small antioxidant molecules because the reaction can be observed visually using common TLC and also its intensity can be analysed by simple spectrophotometric assays [54]. The DPPH radical is scavenged by antioxidants through the donation of hydrogen to form the stable reduced DPPH molecule. The antioxidant radicals formed are stabilized through the formation of non-radical products. This method has been also a useful and widely used to evaluate the free radical-scavenging effectiveness of various antioxidant substances in food systems [55]. In order to investigate the antioxidant activities of the synthesized modified $(+)$-catechin derivatives the DPPH method was used and the results obtained are depicted in Figure 13. 
Figure 13. Free radical scavenging activity of the studied compounds. The results represent the decrease (\%) of the initial $\mathrm{DPPH}^{\bullet}$ absorption at $517 \mathrm{~nm}$.

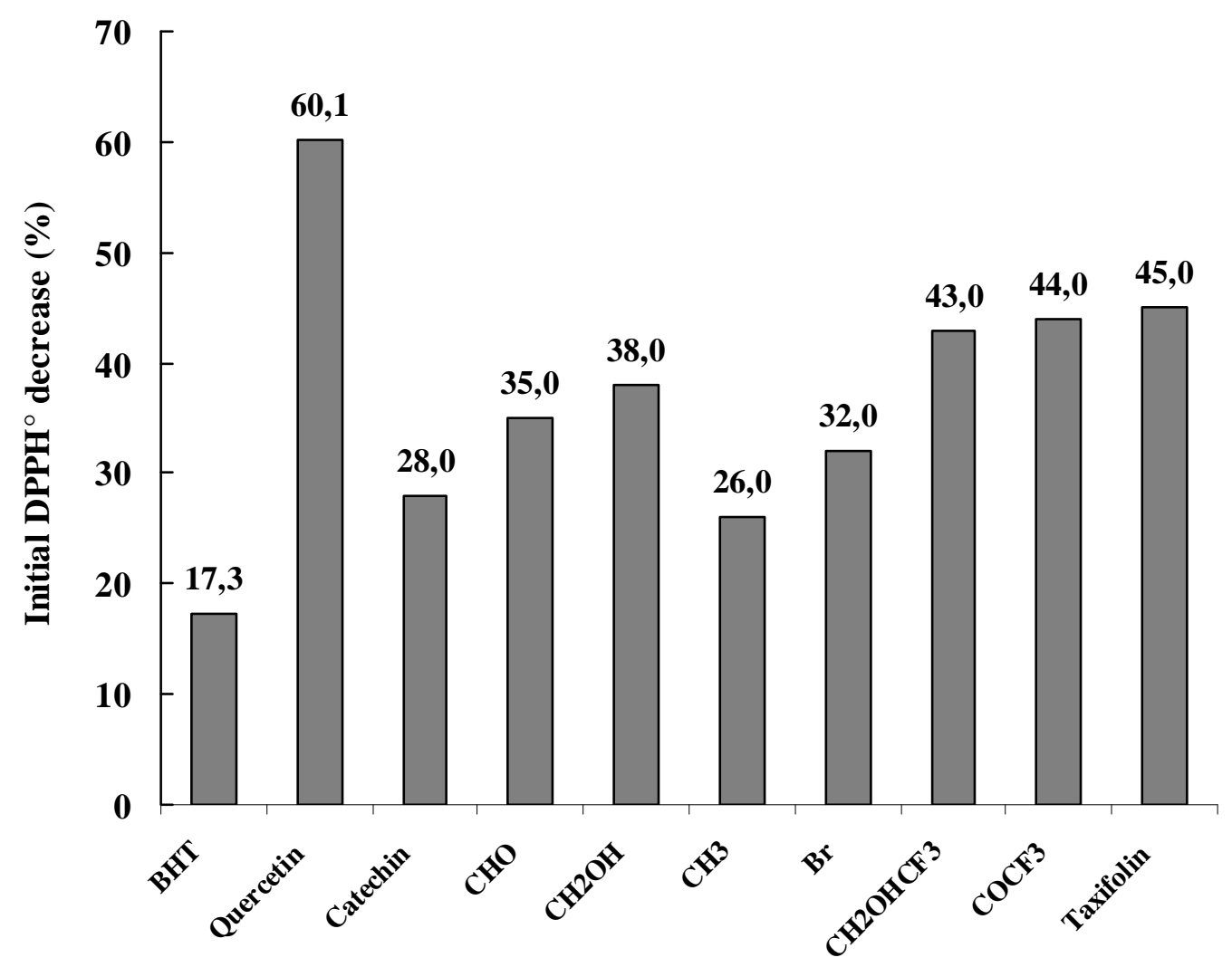

Figure 13 shows the $\mathrm{DPPH}^{*}$ free radical scavenging activity of each compound at a concentration of $10 \mu \mathrm{M}$ where a general decrease in the absorbance at $517 \mathrm{~nm}$ was noticed. This indicated a $\mathrm{DPPH}^{\circ}$ free radical-scavenging activity of the tested compounds. It can be also noticed that most of the synthesized compounds showed obvious scavenging activity on DPPH ${ }^{\bullet}$ radicals. All the modified flavan-3-ols displayed stronger activities than that of BHT and most of them showed better antioxidative activity than (+)-catechin. Among the tested modified flavan-3-ols, compounds 7 $\left(\mathrm{CHOHCF}_{3}\right), \mathbf{8}\left(\mathrm{COCF}_{3}\right)$ and $\mathbf{9}$ (taxifolin) displayed the strongest activity with an absorbance decrease of about 43, 44 and $45 \%$ respectively. And the order of the activities of flavan-3-ol derivatives were showed to be as follow $\mathbf{9}$ (taxifolin) $>\mathbf{8}\left(\mathrm{COCF}_{3}\right)>\mathbf{7}\left(\mathrm{CHOHCF}_{3}\right)>\mathbf{4}\left(\mathrm{CH}_{2} \mathrm{OH}\right)>\mathbf{3}(\mathrm{CHO})>\mathbf{6}(\mathrm{Br})>\mathbf{1 a}$ (catechin) $>5\left(\mathrm{CH}_{3}\right)$, that is, the modified flavan-3-ols with oxygenated and/or hydroxylated subsituents showed much higher antioxidant activities than that of $(+)$-catechin.

The free radical scavenging activity is usually expressed as percentage of $\mathrm{DPPH}^{\bullet}$ inhibition but also by the antioxidant concentration required for a $50 \% \mathrm{DPPH}^{*}$ reduction $\left(\mathrm{IC}_{50}\right)$. A dose-response curve was thus obtained for every product where all the tested compounds showed dose-dependant increase in activity and a spectrophotometric analysis was used in order to determine the inhibition concentration $\left(\mathrm{IC}_{50}\right)$ of the studied samples, which is a widely used parameter for determining radical scavenging capacity of pure samples. $\mathrm{IC}_{50}$ is the amount of antioxidant necessary to determine the initial concentration of $\mathrm{DPPH}^{*}$ radical by $50 \%$. $\mathrm{IC}_{50}$ value is considered to be a good measure of the antioxidant efficiency of pure compounds and extracts.

The obtained results, summarized in Figure 14, showed that the new flavan-3-ol derivatives are potent free radical scavenging agents in the $\mathrm{DPPH}^{\bullet}$ free radical assay. From $\mathrm{IC}_{50}$ the $\mathrm{ED}_{50}$ is 
determined. $\mathrm{ED}_{50}$ represents the number of products ( $\mu$ mole) able to consume half the amount of free radical divided by $\mu$ mole if initial $\mathrm{DPPH}^{*}$. The inverse of $\mathrm{ED}_{50}$ is a measure of the antiradical power (ARP). By multiplying the $\mathrm{ED}_{50}$ by two, the stoichiometric value (theoretical concentration of antioxidant to reduce $100 \%$ of the $\mathrm{DPPH}^{\circ}$ ) is obtained. The inverse of this value represents the moles of $\mathrm{DPPH}^{*}$ reduced by one mole of antioxidant and gives an estimate of the number of hydrogen atoms involved in the process. Table 1 summarizes the parameters obtained. It can be noticed that some of the tested compounds were more efficient than $(+)$-catechin 1a and BHT, being the order of antiradical power $\mathbf{9}$ (taxifolin) $>\mathbf{8}\left(\mathrm{COCF}_{3}\right)>\mathbf{7}\left(\mathrm{CHOHCF}_{3}\right)>\mathbf{4}\left(\mathrm{CH}_{2} \mathrm{OH}\right)>\mathbf{3}(\mathrm{CHO})>\mathbf{6}(\mathrm{Br})>\mathbf{1 a}$ (catechin) $>\mathbf{5}$ $\left(\mathrm{CH}_{3}\right)$. The stoichiometric value obtained for $(+)$-catechin was 0.36 corresponding to the reduction of ca. three DPPH${ }^{*}$. Most of the modified tested flavan-3-ols were able to reduce roughly one more molecule of $\mathrm{DPPH}^{*}$ than the underivatised (+)-catechin. Compound $\mathbf{9}$ is clearly the most efficient of the new tested molecules. Among all the tested compounds, only compound $\mathbf{5}$ with a methyl group as substituent was less active than (+)-catechin. Quercetin, with five hydroxyl groups, donated an average of 4.8 electrons/molecule. Results shown in Table 1 demonstrate that flavonoids which react with $\mathrm{DPPH}^{\circ}$ and donate an electron are those with an oxygenated substituent.

Figure 14. Free radical scavenging activity of the studied compounds. The results represent the concentration $\mathrm{IC}_{50}$ needed to decrease by $50 \%$ the initial $\mathrm{DPPH}^{\bullet}$ absorption at $517 \mathrm{~nm}$.

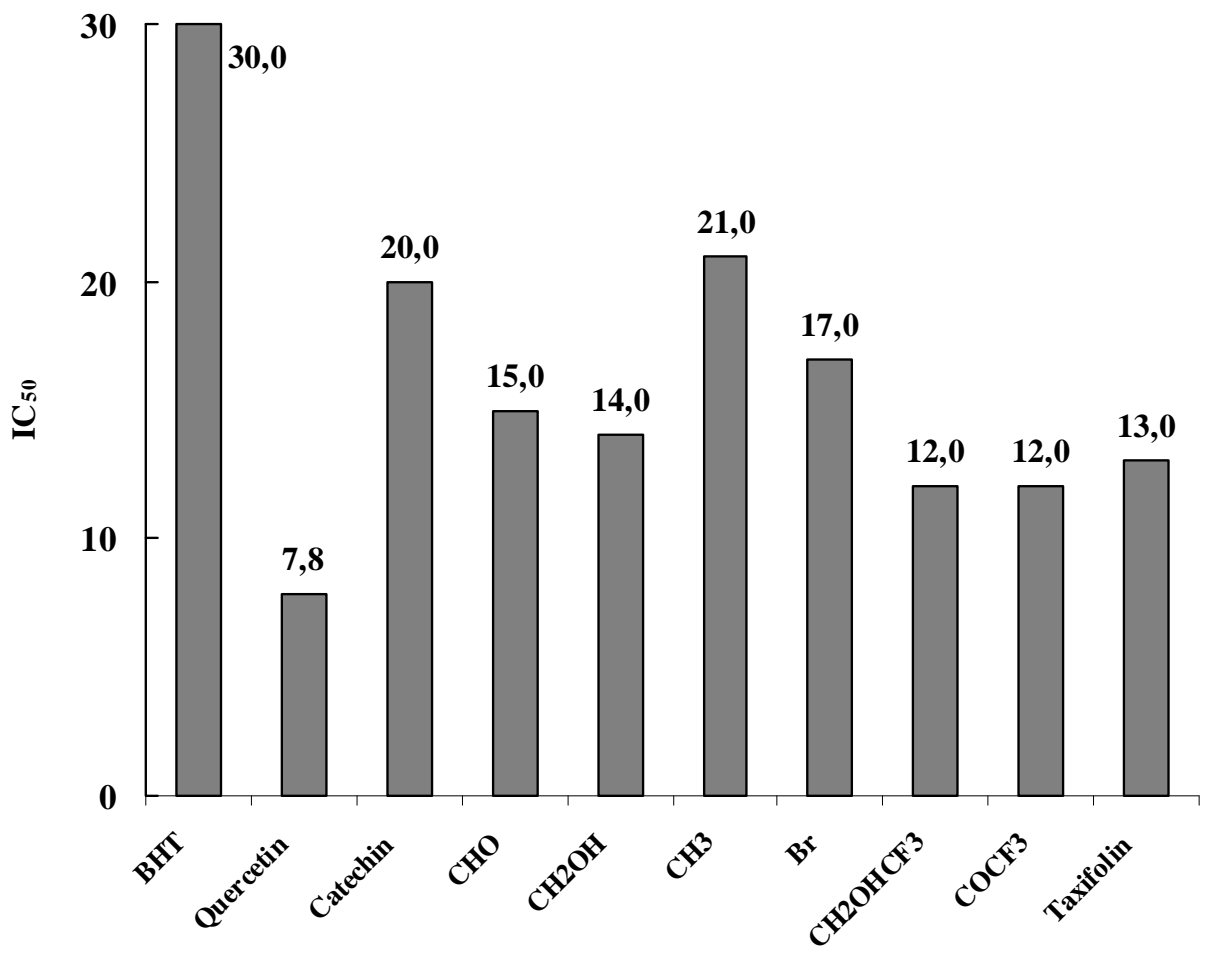


Table 1. Antiradical power and stoichiometry from the DPPH assay.

\begin{tabular}{lcccc}
\hline \multicolumn{1}{c}{ Compound } & ED $_{\mathbf{5 0}}$ & ARP & $\begin{array}{c}\text { Stoichiometric } \\
\text { value }\end{array}$ & $\begin{array}{c}\text { H atoms per } \\
\text { molecule }\end{array}$ \\
\hline BHT & 0.33 & 3.00 & 0.67 & 1.50 \\
37 : Quercetin & 0.10 & 9.60 & 0.21 & 4.80 \\
1a : $(+)-C a t e c h i n$ & 0.18 & 5.60 & 0.36 & 2.80 \\
3: $(\mathrm{CHO})$ & 0.14 & 7.00 & 0.29 & 3.50 \\
4: $\left(\mathrm{CH}_{2} \mathrm{OH}\right)$ & 0.14 & 7.20 & 0.28 & 3.60 \\
5: $\left(\mathrm{CH}_{3}\right)$ & 0.19 & 5.20 & 0.38 & 2.60 \\
6: $(\mathrm{Br})$ & 0.15 & 6.60 & 0.30 & 3.30 \\
7: $\left(\mathrm{CHOHCF}_{3}\right)$ & 0.14 & 7.40 & 0.27 & 3.70 \\
8: $\left(\mathrm{COCF}_{3}\right)$ & 0.13 & 7.60 & 0.26 & 3.80 \\
9: Taxifolin & 0.13 & 8.00 & 0.25 & 4.00 \\
\hline
\end{tabular}

\section{Structure-activity relationships}

Many attempts at explaining the structure-activity relationships of some natural antioxidant compounds have been reported in the literature. It has been reported that the antioxidant activity of phenolic compounds may result from the neutralization of free radicals initiating oxidation processes, or from the termination of radical chain reactions, due to their hydrogen donating ability [56]. It is also known that the antioxidant activity of polyphenolic compounds is closely associated with their structures, such as substitutions on the aromatic ring and side chain structure. Their accessibility to the radical centre of $\mathrm{DPPH}^{*}$ could also influence the order of the antioxidant power. Free radicalscavenging activity of polyphenolic compounds is believed to be influenced by the number and position of phenolic hydrogen in their molecules [42]. It is also proposed that the higher antioxidant activity is related to the greater number of hydroxyl groups on the flavonoid nucleus [57].

In overall agreement with structure-activity relationship studies of the free radical scavenging capacity of flavonoids [42,58], several structural features were shown to be important for the protective effect of flavonoids against glutamate-mediated programmed cell death [59] including the presence of a hydroxyl group on C-3 and a 2-3 double bond in conjugation with a C-4 ketone function. The formation of hydrogen bonds between the ketonic oxygen and the hydroxyls at C-3 and C-5 may have some influence on the scavenging power as well [58].

Catechins do not contain either the unsaturation or the ketone function on C-4 and this is the reason why compounds such as (+)-catechin 1a are less potent scavengers than flavonols such as quercetin. Some catechins such as galloylated or oligomeric derivatives compensate for this by the presence of more hydroxyl groups as well as the ester function at C-3 [42, 60, 61].

While the antioxidative activity of (+)-catechin and its oligomeric forms (procyanidins) was investigated, little is known about the antioxidant activity of 8-modified flavan-3-ols. As shown in table 1 , only one compounds 5 exhibited antioxidant activity lower than $(+)$-catechin, while the results obtained for all the tested compounds were higher than that of (+)-catechin and BHT. In the same conditions quercetin was the most potent antioxidative compound. The substituents on C-8 position of the aromatic A ring appear to have a clear influence of the antioxidant effect of $(+)$-catechin. The 
presence of a group on C-8, which allow for the formation of hydrogen bonds with the hydroxyls either C-7 may play a role in the ability of the $(+)$-catechin conjugates to scavenge free radicals in a manner similar to quercetin. Since the substituent moieties are attached to the side-chain hydroxyl group functionality of the flavanol skeleton, it is unlikely that they affect the aromatic hydroxyl group that is responsible for antioxidant activity.

Flavonoid hydrophobicity has also been proposed to play an important role the free radical scavenging activity. In view of the chemical structure of the compounds active, hydrophobicity may be most crucial. Instead, the 8-substitutents influence might also influence the polarity of the compounds becoming more or less hydrophobic, and thus might give negative/positive influences on their antioxidant activity when assayed in aqueous conditions. This may explain why compound $\mathbf{5}$ with a methyl group presents a lower free radical scavenging activity than $(+)$-catechin.

\section{Conclusions}

In summary, this work represents an overview of our findings concerning the chemical and the enzymatic reactivity of some flavonoids pertaining to the flavanol, flavone and flavonol families. Thus the synthesis and structural characterization of activated monomeric flavanols obtained by substitution with differents groups at the 8 position were achieved and used as precursor for preparation, through various coupling reactions, of natural and modified dimeric procyanidin derivatives. The structures of the formed compounds were characterized on the basis of their MS and NMR spectral analysis. Proton-proton and proton-carbon correlations enable to distinguish between the different flavanol moieties and to establish their sequence. The obtained results showed the importance of electronic features in the establishment of the carbon-carbon interflavanic bond.

Through the enzymatic oxidation products of three flavonols, 36-38, we were able to prove the first oxidation to occur not on the phenolic functions but on the hydroxy group at $\mathrm{C} 3$, resulting in the major formation of C2 oxidized products. However, the presence of phenolic groups on the B ring is an important feature in the stabilizing of phenyl radicals, which can undergo coupling reactions. Moreover, when observed, these phenyl or phenoxyl radicals do not undergo dismutation since it would results in the formation of quinones (Figure 9), which would rather undergo nucleophilic addition reaction with other flavanol monomers, resulting in the formation of C2'(or C3')-C8(or C6) dimers as already reported in the literature in the case of flavan-3-ols [22].

Finally, the free radical scavenging activity of some modified (+)-catechin derivatives was explored and their efficacy was compared with that of quercetin, BHT and (+)-catechin. The obtained results showed that some of the studied compounds present relatively higher free radical scavenging activity that $(+)$-catechin indicating that the introduction of a substituent onto position 8 of (+)-catechin yielded compounds with improved antiradical efficacy in solution. These compounds could thus protect human cells from oxidative stress-induced death. 


\section{Acknowledgements}

The authors wish to thank L. Kerhoas (INRA, Versailles) for MS experiments, C. Le Guernevé (INRA, Montpellier) and M.-T. Martin (CNRS, ICSN, Gif-sur-Yvette) for NMR HMBC and HSQC experiments.

\section{References}

1. Macheix, J. J.; Fleuriet, A.; Billot, J. Fruit phenolics; CRC Press: Boca Raton, Florida, USA, 1990.

2. Dixon, R. A.; Achnine, L.; Kota, P.; Liu, C. J.; Reddy, M. S. S.; Lang, L. J. The phenylpropanoid pathway and the plant defence-A genomic perspective. Mol. Plant Pathol. 2002, 3, 371-390.

3. Debeaujon, I.; Léon-Kloosterziel, K. M.; Koomneef, M. Influence of the testa on seed doemancy, germination and longevity in Arabidopsis. Plant Physiol. 2000, 122, 403-414.

4. Pourcel, L.; Routaboul, J.-M.; Kerhoas, L.; Caboche, M.; Lepiniec, L. Transparent Testa 10 encodes a laccases-like enzyme involved in oxidative polymerization of flavonoids in Arabidopsis seed coat. The Plant Cell 2005, 17, 2966-2980.

5. Winkel-Shirley, B. Biosynthesis of flavonoids and effects of stress. Curr. Opin. Plant Biool. 2002, 5, 218-223.

6. Harborne, J.B.; Williams, C.A. Advances in flavonoid research since 1992. Phytochemistry 2000, 55, 481- 504.

7. Ferreira, D.; Bekker, R. Oligomeric proanthocyanidins: Naturally occurring O-heterocycles. Nat. Prod. Rep. 1996, 13, 411-433.

8. Porter, L. J. Flavans and proanthocyanidins. In The flavonoids: advances in research since 1986; Harborne, J. B., Ed.; Chapman and Hall: New York, 1994; pp. 23-54.

9. Ferreira, D.; Nel, R. J. J.; Bekker, R. In Comprehensive Natural Products Chemistry; Barton, D. H. R.; Nakanishi, K.; Meth-Cohn, O.; Pinto, B. M., Eds.; Elsevier: New York, 1999; Vol. 3, pp. 747-797.

10. Ferreira, D.; Brandt, E. V.; Coetzee, J.; Malan, E. Condensed tannins. In The Chemistry of Organic Natural Products, Zechmeister, L.; Herz, W; Falk, H.; Kirby G. W.; Moore, R. E., Eds.; Springer Verlag: Wien, 1999; Vol. 77, pp. 21-67.

11. Ariga, T.; Koshiyama, I.; Fukoshima, D. Antioxidative properties of procyanidin B1 and B3 from azuki beans in aqueous systems. Agric. Biol. Chem. 1988, 52, 2717-2722.

12. Landrault, N.; Poucheret, P.; Ravel, P.; Gasc., F.; Cros, G.; Teisseidre, P.-L. Antioxidant capacities and phenolics levels of french wines from different varieties and vintages. J. Agric. Food Chem. 2001, 49, 3341-3348.

13. Zhao, J.; Wang, J.; Chen, Y.; Agarwal, R. Anti-tumor-promoting activity of a polyphenolic fraction isolated from grape seeds in the mouse skin two-stage initiation-promotion protocol and identification of procyanidin B5-3'-gallate as the most effective antioxidant constituent. Carcinogenesis 1999, 20, 1737-1745.

14. Es-Safi, N.-E.; Le Guernevé, C., Kerhoas, L.; Ducrot, P.-H. Influence of an 8-trifluoroacetyl group on flavanol couplings. Tetrahedron 2006, 62, 2705-2714. 
15. Beauhaire, J.; Es-Safi, N.-E.; Boyer, F. D.; Kerhoas, L.; Le Guernevé, C.; Ducrot, P.-H. Synthesis of modified proanthocyanidins: Introduction of acyl substituents at C-8 of catechin.Selective synthesis of a C-4 O C-3 Ether-linked Procyanidin-like Dimer. Bioorg. Med. Chem. Lett. 2005, 15, 559-562.

16. Boyer, F. D.; Ducrot, P.-H. Hydrogenation of substituted aromatic aldehydes: nucleophilic trapping of the reaction intermediate, application to the efficient synthesis of methylene linked flavanol dimers. Tetrahedron Lett. 2005, 46, 5177-5180.

17. Es-Safi, N.-E.; Ducrot, P.-H. Oxidation of flavan-3-ol; gram-scale synthesis of taxifolin. Lett. Org. Chem. 2006, 3, 231-234.

18. Boyer, F. D.; Es-Safi, N.-E.; Beauhaire, J.; Le Guernevé, C.; Ducrot, P.-H. Synthesis of modified proanthocyanidins: Easy and general introduction of an hydroxy group at C-6 of catechin; efficient synthesis of elephantorrhizol. Bioorg. Med. Chem. Lett. 2005, 15, 563-566.

19. Boyer, F. D.; Beauhaire, J.; Martin, M.-T.; Ducrot, P.-H. Hydroxylation of ring A of flavan-3-ols: Influence of ring-A substitution pattern on the oxidative rearrangement of 6-hydroxy flavan-3-ols. Synthesis 2006, 19, 3250-3260.

20. Dehon, L.; Machex, J. J.; Durand, M. Involvement of peroxidases in the formation of the brown coloration of heartwood in Juglans nigra. J. Exp. Bot. 2002, 53, 303-311.

21. Lopez-Serrano M.; Barcelo, A. R. Comparative study of the products of the peroxidase catalyzed and the polyphenol oxidase catalyzed (+)-catechin oxidation. Their possible implication in strawberry (Fragaria x Ananassa) browning reactions. J. Agric. Food Chem. 2002, 50, 12181224.

22. Guyot, S.; Vercauteren, J.; Cheynier, V. Structural determination of colourless and yallow dimers resulting from (+)-catechin coupling catalyzed by grape polyphenol oxidase. Phytochemistry 1996, 42, 1279-1288.

23. Claus, H. Laccases: structure, reactions, distribution. Micron 2004, 35, 93-96.

24. Riva, S. Laccases: blue enzymes for green chemistry. Trends Biotech. 2006, 24, 219-226.

25. Bertrand, T.; Jolivalt, C.; Briozzo, P.; Caminade, E.; Joly, N.; Madzak, C.; Mougin, C. Crystal structure of a four-copper laccase complexed with an aryl amine: insights into substrate recognition and correlation with kinetics. Biochemistry 2002, 41, 7325-7333.

26. Kollmann, A.; Boyer, F.-D.; Ducrot, P.-H.; Kerhoas, L.; Jolivalt, C.; Touton, I.; Einhorn, J.; Mougin, C. Oligomeric compounds formed from 2,5-xylidine (2,5-dimethylaniline) are potent enhancers of laccase production in Trametes versicolor ATCC 32745. Appl. Microb. Biotech. 2005, 68, 251-258.

27. Steenkamp, J. A.; Ferreira, D.; Roux, D. G. Stereospecific functionalization of the heterocyclic ring systems of flavan-3-OL and [4,8]-biflavan-3-OL derivatives with 2,3-dichloro-5,6-dicyano1,4-benzoquinone (DDQ). Tetrahedron Lett. 1985, 26, 3045- 3048.

28. Steenkamp, J. A.; Mouton, C. H. L.; Ferreira, D. Regio- and stereoselective oxidation of flavan-3ol- 4-arylflavan-3-ol- and biflavanoid derivatives with 2,3-dichloro-56-dicyano-1,4-benzoquinone (DDQ). Tetrahedron 1991, 47, 6705-6716.

29. Tückmantel, W.; Kozikowski, A. P.; Romanczyk, L. J. Jr. Studies in polyphenol chemistry and bioactivity. 1. Preparation of building blocks from (+)-catechin. Procyanidin formation. Synthesis 
of the cancer cell growth inhibitor, 3-O-galloyl-(2R,3R)-epicatechin-4 $\beta, 8$-[3-O-galloyl-(2R,3R)epicatechin]. J. Am. Chem. Soc. 1999, 121, 12073-12081.

30. Saito, A.; Nakajima, N.; Tanaka, A.; Ubukata, M. Synthetic studies of proanthocyanidins. Part 2: Stereoselective gram-scale synthesis of procyanidin-B3 Tetrahedron 2002, 39, 7829-7837.

31. Kawamoto, H.; Nakatsubo, F.; Murakami, K. Synthesis of condensed tannin derivatives regiosepecifically linked through a single interflavanoid-linkage and their protein-precipitating capacities. Mokuzai Gakkaishi 1991, 37, 488-493.

32. Yoneda, S.; Kawamoto, H.; Nakatsubo, J. Yoneda, S.; Kawamoto, H.; Nakatsubo, F. Synthesis of high molecular mass condensed tannin by cationic polymerization of flavan 3,4 carbonate. $J$. Chem. Soc. Perkin Trans. I 1997, 1025-1030.

33. Steinberg, P. J.; Nel, R. J. J.; Van Rensburg, H.; Bezuidenhoudt, B. C. B.; Ferreira, D. Oligomeric flavanoids. Part 27. Interflavanyl bond formation in procyanidins under neutral conditions. Tetrahedron 1998, 54, 8153-8158.

34. Arnaudinaud, V.; Nay, B.; Verge, S.; Nuhrich, A.; Deffieux, G.; Merillon, J. -M.; Monti, J. -P.; Vercauteren, J. Total synthesis of isotopically labelled flavonoids. Part 5: Gram-scale production of ${ }^{13}$ C-labelled (-)-procyanidin B3. Tetrahedron Lett. 2001, 42, 5669-5671.

35. Arnaudinaud, V.; Nay, B.; Verge, S.; Nuhrich, A.; Deffieux, G.; Merillon, J. -M.; Monti, J. -P.; Vercauteren, J. Total synthesis of isotopically labelled flavonoids. Part 3: ${ }^{13} \mathrm{C}$-labelled (-)procyanidin B3 from 1-[ $\left.{ }^{13} \mathrm{C}\right]$-acetic acid. Tetrahedron Lett. 2001, 42, 1279-1281.

36. Delcour, J. A.; Ferreira, D.; Roux, D. G. Synthesis of condensed tannins part 9. The condensation sequence of leucocyanidin with $(+)$-catechin and with the resultant procyanidins. J. Chem. Soc. Perkin Trans. I 1983, 1711-1717.

37. Bennie, L.; Coetzee, J.; Malan, E.; Woolfrey, J. R.; Ferreira, D. Oligomeric flavanoids. Part 34: Doubly-linked proteracacinidin analogues from Acacia caffra and Acacia galpinii. Tetrahedron 2001, 57, 661-667.

38. Balas, L.; Vercauteren, J. Extensive high-resolution reverse 2D NMR analysis for the structural elucidation of procyanidin oligomers. Mag. Reson. Chem. 1994, 32, 386-393.

39. Salas, E.; Atanasova, V.; Poncet-Legrand, C.; Meudec, E.; Mazauric, J.; Cheynier, V. Demonstration of the occurrence of flavanol-anthocyanin adducts in wine and in model solutions. Anal. Chim. Acta 2004, 513, 325-332.

40. Fenoll, L. G.; Garcia-Ruiz, P. A.; Varon, R.; Garcia-Canovas, F. Kinetic study of the oxidation of quercetin by mushroom tyrosinase. J. Agric. Food Chem. 2003, 51, 7781-7787.

41. Van Acker, S. A. B. E.; De Groot, M. J.; Van den Berg, D. J.; Tromp, M. N. J. L.; Den Kelder, G. D. O.; Van der Vijgh, W. J. F. A quantum explanation of the antioxidant activity of flavonoids. Chem. Res. Toxic. 1996, 9, 1305-1312.

42. Rice-Evans, C. A.; Miller, N. J.; Paganga, G. Stucture antioxidant activity relationships of flavonoids and phenolic acids. Free Rad. Biol. Med. 1996, 20, 933-956.

43. Steiner, R. A.; Kalk, K. H.; Dijkstra, B. W. Anaerobic enzyme-substrate structures provide an insight into the reaction mechanism of the copper dependent quercetin 2,3-dioxygenase. Proc. Nat. Acad. Sci. 2002, 99, 16625-16630. 
44. Balogh-Hergovich, E.; Keiser, J.; Speier, G. Synthesis and characterization of copper(I) and copper(II) flavonolate complexes with phthalazine, and their oxygenation and relevance to quercetinase. Inorg. Chim. Acta 1997, 256, 9-14.

45. Enguita, F. J.; Marçal, D.; Martins, L. O.; Grenha, R.; Henriquest, A. O.; Lindley, P. F.; Garrondo, M. A. Substrate and dioxygen binding to the endospore coat laccase from Bacillus subtilis. J. Biol. Chem. 2004, 279, 23472-23476.

46. Trouillas, P.; Fagnère, C.; Lazzaroni, R.; Caliste, C. A.; Marfak, A.; Duroux, J. L. A theoretical study of the conformational behavior and electronic structure of taxifolin correlated with the free radical scavenging activity. Food Chem. 2004, 88, 571-582.

47. Trouillas, P.; Marsal, P.; Siri, D.; Lazzaroni, R.; Duroux, J.-L. A DFT study off the reactivity of $\mathrm{OH}$ groups in quercetin and taxifolin antioxidants: the specificity of the $3-\mathrm{OH}$ site. Food Chem. 2006, 97, 679-688.

48. Krishnamachari, V.; Levine, L. H.; Paré, P. W. Flavonoid oxidation by the radical generator AIBN: a unified mechanism for quercetin radical scavenging. J. Agric. Food Chem. 2002, 50, 4357-4363.

49. Hvattum, E.; StenstrØm, Y.; Ekeberg, D. Study of the reaction products of flavonols with 2,2diphenyl-1-picrylhydrazyl using liquid chromatography coupled with negative electrospray ionization tandem mass spectrometry. J. Mass Spectrom. 2004, 39, 1570-1581.

50. Jimenez M.; Garcia-Carmona, F. Myricetin, an antioxidant flavonol, is a substrate of polyphenol oxidase. J. Sci. Food Agric. 1999, 79, 1993-2000.

51. Yokozawa, T.; Chen, C.P.; Dong, E.; Tanaka, T.; Nonaka, G.I.; Nishioka, I. Study on the inhibitory effect of tannins and flavonoids against the 1,1-diphenyl-2-picrylhydrazyl radical. Biochem. Pharmacol. 1998, 56, 213-222.

52. Belinky, P. A.; Aviram, M.; Fuhrman, B.; Rosenblat, M.; Vaya, J. The antioxidative effects of the isoflavan glabridin on endogenous constituents of LDL during its oxidation. Atherosclerosis 1998, 137, 49-61.

53. Bondet, V.; Brand-Williams, W.; Berset, C. Kinetics and mechanism of antioxidant activity using the DPPH` free radical methods. Lebensm.-Wiss. Technol. 1997, 30, 609-615.

54. Sanchez-Moreno, C.; Larrauri, J.A.; Sauro-Calixto, F.A. Procedure to measure the antiradical efficiency of polyphenols. J. Sci. Food Agric. 1998, 76, 270-276.

55. Cotelle, N.; Bernier, J.L.; Catteau, J.P.; Pommery, J.; Wallet, J.C.; Gaydou, E.M. Antioxidant properties of hydroxyl-flavones. Free Rad. Biol. Med. 1996, 20, 35-43.

56. Baumann, J.; Wurn, G.; Bruchlausen, F.V. Prostaglandin synthase inhibiting $\mathrm{O}_{2}{ }^{-}$radical scavenging properties of some flavonoids and related phenoic compounds. N-Ss Arch. Pharmacol. 1979, 308, R27-R39.

57. Cao, G.; Sofic, E.; Prior, R.L. Antioxidant and prooxidant behaviour of flavonoids: structureactivity relationships. Free Rad. Biol. Med. 1997, 22, 749-760.

58. Bors, W.; Heller, W.; Michel, C.; Saran, M. Flavonoids as antioxidants: determination of radicalscavenging efficiencies. In Methods in enzymology; Packer, L., Ed.; Academic Press: San Diego, 1990; pp. 343-355.

59. Ishige, K.; Schubert, D.; Sagara, Y. Flavonoids protect neuronal cells from oxidative stress by three distinct mechanisms. Free Rad. Biol. Med. 2001, 30, 433-446. 
60. Bors, W.; Michel, C.; Stettmaier, K. Electron paramagnetic resonance studies of radical species of proanthocyanidins and gallate esters. Archiv. Biochem. Biophys. 2000, 374, 347-355.

61. Bors, W.; Michel, C.; Stettmaier, K. Structure-activity relationships governing antioxidant capacities of plant polyphenols. Methods Enzymol. 2001, 335, 166-180.

Sample Availability: Samples are not available.

(C) 2007 by MDPI (http://www.mdpi.org). Reproduction is permitted for noncommercial purposes. 